ISSN: 0514-7336

DOI: http://dx.doi.org/10.14201/zephyrus2014746587

\title{
LA ARTESANÍA DE LOS BRAZALETES LÍTICOS DE LA CUEVA-SIMA DE LA SERRETA (CIEZA, MURCIA): TECNOLOGÍA, ÚTILES Y FUNCIONALIDAD DEL SITIO
}

\section{The Crafts of the Stone Bracelets in the Cueva-Sima de La Serreta (Cieza, Murcia): Technology, Tools and Functionality of the Site}

\author{
Francisco Martínez-Sevilla* y Joaquín Salmerón Juan** \\ * Dpto. de Prehistoria y Arqueología. Facultad de Filosofía y Letras. Campus Universitario de Cartuja, s/n. 18071 \\ Granada.Correo-e:martinezsevilla@ugr.es \\ ** Servicio de Patrimonio Histórico. Ayto. de Cieza. Plaza Mayor, 1.30530 Cieza (Murcia). Correo-e: segisa@gmail.com
}

Recepción: 10/02/2014; Revisión:10/07/2014; Aceptación: 15/09/2014

BIBLID [0514-7336 (2014) LXXIV, julio-diciembre; 65-87]

Resumen: Se estudia un conjunto de brazaletes de piedra, acabados y en proceso de elaboración, de la Cueva-Sima de La Serreta, así como los útiles y técnicas empleados en el proceso de manufactura. La metodología de trabajo se ha basado en el estudio tecnológico, traceológico y tipológico de los restos de elaboración y los productos manufacturados. El análisis de este registro material ha permitido extraer conclusiones sobre el uso de la cueva y su ocupación. La extracción de roca de la pared de la cavidad afectó a una de las pinturas rupestres, lo que nos ha permitido determinar que la cronología de las pinturas puede ser anterior o sincrónica a la artesanía de los brazaletes. De igual forma, la identificación de las técnicas que componen la cadena operativa de elaboración de los brazaletes de piedra ha permitido reconocer procedimientos propios y particulares de este taller que lo diferencian del resto de los estudiados. La situación geográfica del taller de La Serreta viene a remarcar las relaciones culturales entre poblaciones neolíticas del Sur y el Levante de Iberia.

Palabras clave: Neolítico; Adornos; Taller; Artesanos; Cadena operativa.

Авsтract: We study a set of stone bracelets, finished and in process, from the Cueva-Sima de La Serreta, as well as the tools and techniques used in the manufacturing process. The working methodology is based on technological, use-wear and typological analysis of manufacture residues and finished product. The study of this material record has allowed conclusions about the use of the cave and occupation. The rock extraction of the cavity wall affected a rock paintings. It has allowed us to determine the chronology of the paintings may be earlier or synchronous to the crafts of the of the bracelets. Likewise, identifying techniques that make up the operational chain of processing stone bracelets, has led a recognition own features of this workshop that differ from the rest of workshops studied. The geographical location of La Serreta workshop is to highlight cultural relations between Neolithic populations of the South and the East of Iberia.

Key words: Neolithic; Ornaments; Workshop; Craftsmen; Chaîne opératoire. 


\section{Introducción ${ }^{1}$}

En este trabajo se presenta el proceso tecnológico de elaboración de brazaletes de piedra en la Cueva-Sima de La Serreta. La relevancia de este yacimiento especializado viene dada por varias características del mismo: de los veinte talleres conocidos en la actualidad (Martínez-Sevilla, 2013b) es el situado más al E de todo el conjunto; la excavación arqueológica que se llevó a cabo ha permitido documentar todo el proceso de manufactura, así como los útiles implicados en él; y, finalmente, algunas de las técnicas empleadas difieren del resto de los talleres estudiados por nosotros, lo que permite afirmar un desarrollo local de esta artesanía.

Los brazaletes de piedra destacan entre los conjuntos artefactuales del Neolítico del s peninsular desde el punto de vista numérico y cualitativo; estos se dividen tecnotipológicamente entre anchos y estrechos, elaborados en diferentes litologías como mármol, caliza, dolomías, pizarra o esquistos. Los estudios se han centrado en su clasificación formal (Teruel, 1986), distribución territorial a partir de la tipología (Jiménez, 1979) y en los análisis petrográficos (Gavilán y Rafael, 1999). Las aportaciones sobre la tecnología de elaboración no han sido numerosas y se han basado en la ordenación y clasificación de los desechos de la producción de brazaletes estrechos en el yacimiento almeriense de Cabecicos Negros (Vera) (Goñi, 1999; Goñi et al., 1999). Por nuestra parte, las investigaciones que venimos realizando se han centrado en el reconocimiento de la tecnología de elaboración, tomando como referentes el análisis del registro arqueológico y la contrastación con la creación de referentes experimentales ${ }^{2}$. Así, hemos podido definir las técnicas que componen los métodos de manufactura de los brazaletes, tanto estrechos (Martínez-Sevilla

\footnotetext{
1 Queremos expresar nuestro agradecimiento a A. Morgado Rodríguez, F. Jiménez Cobos y J. Carrasco Rus por las apreciaciones hechas sobre el texto que, sin duda, han mejorado sustancialmente la forma y el contenido del presente artículo.

${ }^{2}$ Este trabajo se enmarca en el proyecto de tesis doctoral que con el título: "Un adorno reflejo de una sociedad. Los brazaletes líticos del Neolítico en Iberia (VI-V milenio a.C.) tecnología, funcionalidad y circulación" está siendo desarrollado por el primer firmante.
}

y Maeso, 2011), como anchos (Martínez-Sevilla, 2010, 2013a) y la distribución espacial de esta producción artesanal (Martínez-Sevilla, 2013b).

El conjunto material analizado en La Serreta está constituido por un total de 93 brazaletes, de los cuales 15 están acabados (Fig. 13) y el resto (78) se encuentran en diferentes fases del proceso de elaboración, bien fracturados o abandonados (Fig. 14). De igual forma, se han estudiado las herramientas utilizadas en el proceso, de las cuales se muestra una selección atendiendo a su clasificación tecnofuncional. La perspectiva de análisis de este trabajo es dinámica, ya que el propio concepto de producción implica analizar todo el ciclo productivo: el aprovisionamiento de la materia prima, el proceso técnico de manufactura, el uso social de los productos y su abandono. Los materiales arqueológicos estudiados han sido documentados en las diferentes prospecciones y excavaciones realizadas en la cavidad y actualmente se encuentran depositados en el Museo Arqueológico 'Medina Siyâsa' de Cieza (Murcia).

\section{La Cueva-Sima de La Serreta: contexto geográfico y cronocultural}

La Serreta se localiza en el denominado Cañón de los Almadenes, ubicado entre los términos municipales de Calasparra y Cieza (Murcia). El cañón ha sido modelado por el río Segura a su paso por las sierras del Molino -826 m.s.n.m.- y la Palmera -655 m.s.n.m.-, aprovechando las líneas de fractura y mediante procesos de disolución de las rocas carbonatadas. Así se formó un cañón de varios kilómetros de longitud y paredes verticales que en algunos casos pueden llegar a los $120 \mathrm{~m}$ de profundidad, sobre calizas y dolomías del Cretácico superior del Prebético de la Cordillera Bética (Fig. 1).

El yacimiento se encuentra en la margen izquierda del río Segura y se trata de una cueva colgada formada por una diaclasa. La calificación de cueva-sima le viene dada por su entrada cenital conformada por una sima de $12,5 \mathrm{~m}$ de profundidad dividida en dos tramos: una amplia cornisa de 7,5 m y otra caída de $5 \mathrm{~m}$ que da acceso a la cavidad. La galería principal, de $35 \mathrm{~m}$ de longitud, está inclinada en dirección $\mathrm{N}$-s hasta abrirse al Cañón de los Almadenes $-60 \mathrm{~m}$ por debajo- en una ventana de unos $8 \mathrm{~m}$ de altura por 9 de anchura en su 


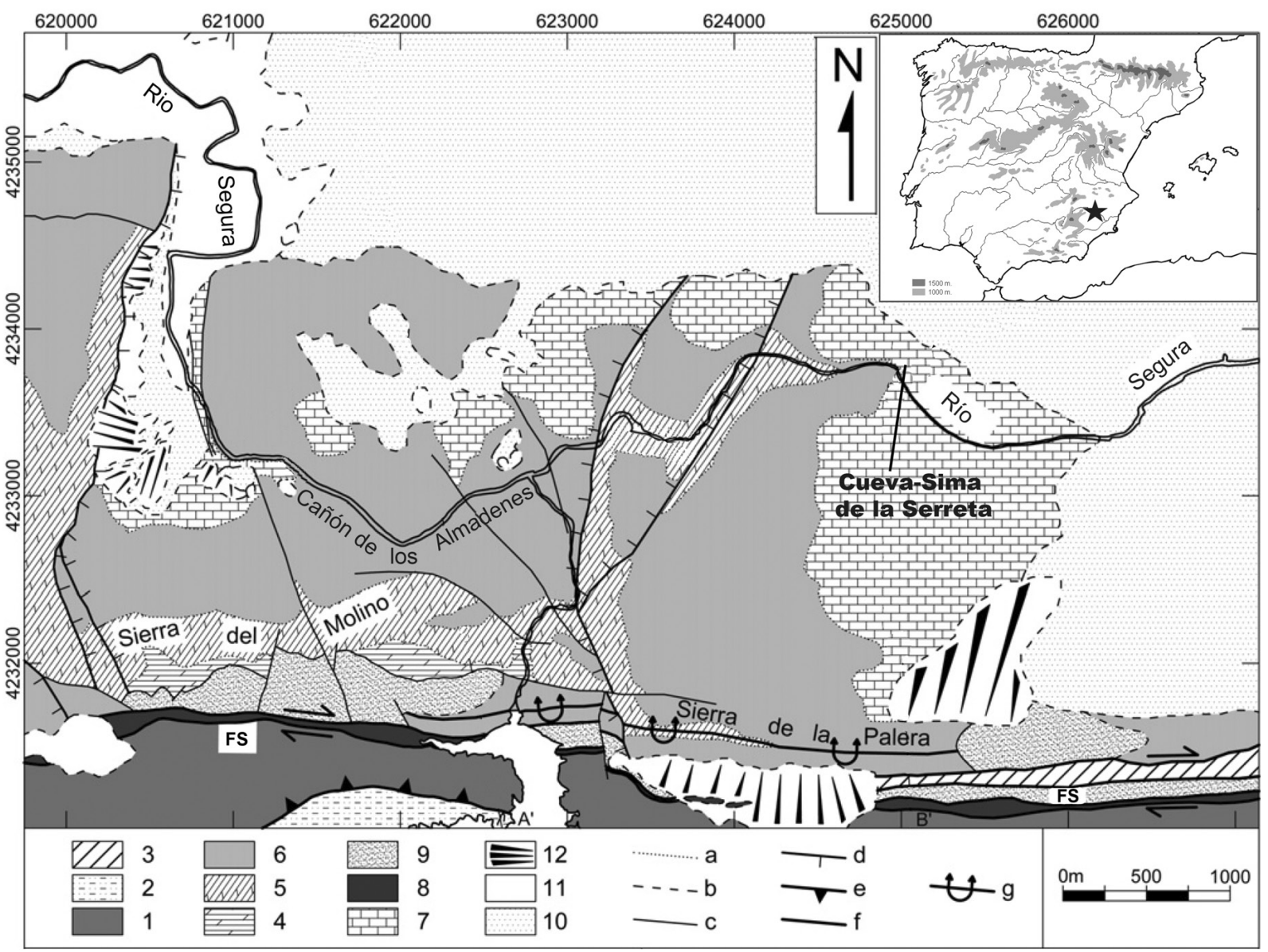

Fig. 1. Localización geográfica de La Serreta y su contexto geológico: (1) yesos, areniscas y limonitas del Triásico y calizas del Cretácico inferior; (2) marga; (3) arenas y conglomerados del Cretácico superior; (4) dolomía estructurada; (5) dolomía estratificada; (6) dolomía sin estructuras; (7) caliza; (8) caliza del Eoceno; (9) conglomerados del Mioceno medio, caliza y margas bioclásticas; (10) calizas del Mioceno superior; calizas y margas bioclásticas del Cuaternario; (11) conglomerado; (12) Conos de deyección. (a) contacto estratigráfico; (b) discordancia; (c) fallas menor; (d) fallas normales; (e) fallas inversas; (d) falla de desgarre; FS= Falla de Socovos (modificado a partir de Sánchez-Gómez et al., 2011).

parte baja. Alrededor de esta sala principal se abren otras de menores dimensiones y un tubo a presión de $13 \mathrm{~m}$ de longitud. El relleno sedimentario de la cavidad no es muy potente, pero en la parte central puede llegar a $1,5 \mathrm{~m}$ de profundidad. A nivel morfológico, destacan tres grandes bloques caídos de la techumbre al igual que la ausencia de formaciones estalagmíticas, salvo dos coladas de pequeño tamaño (Fig. 2, n. ${ }^{\text {os }} 1$ y 2 ).

La Serreta fue descubierta por el Servicio de Exploraciones e Investigaciones Subterráneas de la Diputación Provincial de Murcia en el año 1972 (Sánchez et al., 1975). Desde su hallazgo las pinturas rupestres han sido el principal objeto de estudio en múltiples trabajos (Sánchez et al., 1975; San Nicolás del Toro, 1985; García del Toro, 1988; Mateo, 1996 y 1997)³, hasta la publicación de los primeros materiales arqueológicos de prospección (Salmerón, 1989). Las primeras actuaciones arqueológicas se llevaron a cabo con motivo del cerramiento de la entrada y la colocación

3 Cf. también San Nicolás del Toro, M.: Aportaciones al estudio del arte rupestre en Murcia. Memoria de licenciatura inédita, presentada en 1980 en la Univ. de Murcia. 
68 F. Martínez-Sevilla y J. Salmerón / La artesanía de los brazaletes líticos de la Cueva-Sima de La Serreta (Cieza, Murcia)...

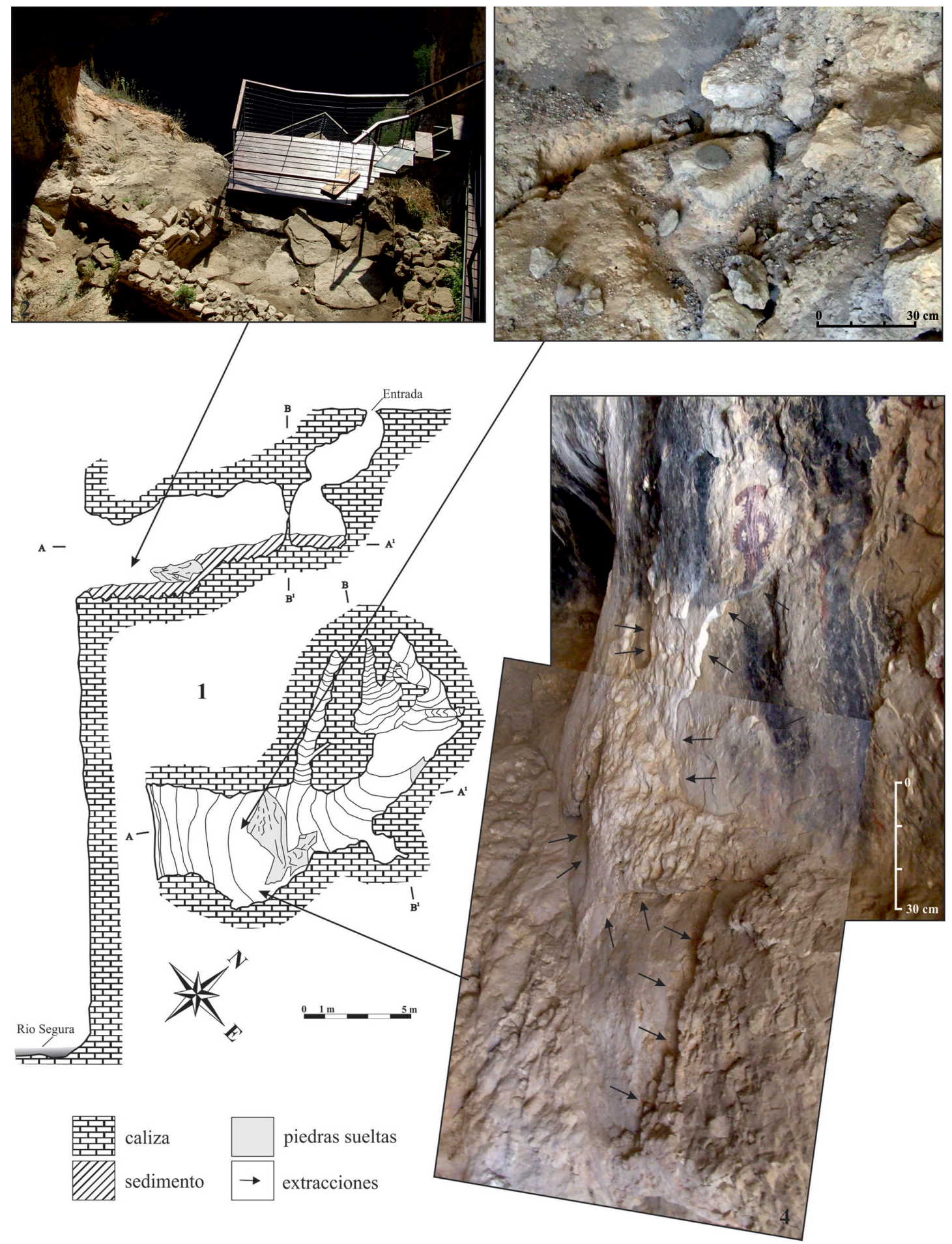

Fig. 2. Cueva-Sima de la Serreta: 1) planta y sección; 2) vista desde el interior hacia el Cañón de los Almadenes; 3) área de producción de brazaletes y pulidor in situ; 4) pintura rupestre y restos de cantería en una de las paredes de la cavidad; obsérvese el detalle de la destrucción de la pintura por la extracción de caliza. 
de una escalera metálica para acceder a la sala principal. Estos sondeos permitieron tener una valoración inicial de la secuencia de la cavidad; entre las fases documentadas destacaban los materiales neolíticos (Martínez Sánchez, 1996). Tras estos trabajos iniciales se llevó a cabo el grueso de las actuaciones arqueológicas centradas en la ocupación neolítica y romana de la cavidad (Salmerón, 1993, 1994, 1995a, 1995b, 1996, 1997 y 1999).

En definitiva, la secuencia estratigráfica señala una ocupación prolongada que se iniciaría durante el Neolítico, con fases de la Edad del Cobre y Bronce difícil de definir a excepción de dos elementos metálicos: una punta tipo Palmela y un puñal, así como ciertas formas cerámicas abiertas. Las fases históricas de la cavidad se inician con una vivienda de época romana del s. III d. C. (Fig. 2, n. ${ }^{\circ} 2$ ), y finalmente una ocupación medieval islámica de los ss. X al XIII.

El periodo que ha aportado una mayor documentación y del que nos ocupamos en este trabajo es el Neolítico. En el extremo s de la cavidad se han hallado dos estructuras excavadas en la terra rosa estéril, que constituye un pavimento allanado artificialmente, amortizadas con un relleno de materiales cerámicos, útiles macrolíticos, elementos en sílex, cuarcita y semillas de trigo y cebada. En el inmediato entorno de estas estructuras

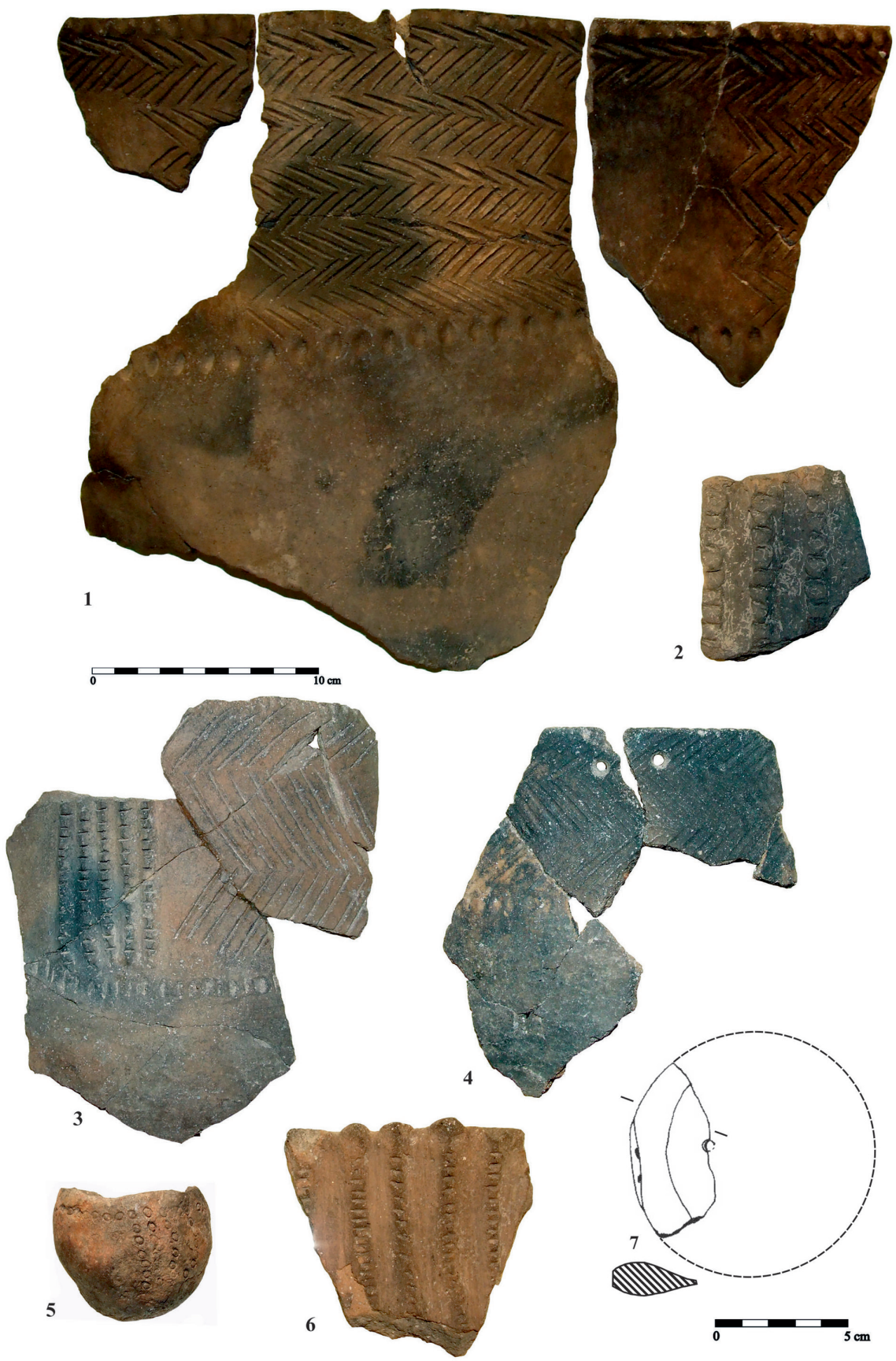

FIG. 3. Cerámicas decoradas pertenecientes a los niveles neoliticos de la cavidad: 1) vasija de almacenamiento con decoraciones impresas en espiga y digitaciones; 2) cordones con digitaciones; 3) vasija globular con decoraciones incisas en espiga, cordones con incisiones y ungulaciones; 4) vasija globular con decoraciones impresas en espiga; 5) vasito con decoración impresa con matriz circular; 6) cordones con incisiones; 7) fragmento de brazalete en elaboración con perforación. 
excavadas, a menos de $3 \mathrm{~m}$ hacia el se, se documentó también la existencia de dos hogares; otras estructuras excavadas de pequeño tamaño, que podrían interpretarse como reposaderos para vasijas o para soportar alguna estructura orgánica y un pulidor in situ (Fig. 2, n.o 3).

El material cerámico presenta un alto índice de fragmentación. Las formas de las vasijas son de tendencia globular con bordes entrantes y rectos pero, también están representados los cuencos hemisféricos y otras vasijas con formas abiertas. El tamaño de los recipientes es medio y grande. Los labios de los bordes son generalmente redondeados, planos y semiplanos, aunque también presentan en ocasiones formas biseladas y redondeadas-apuntadas. La mayoría de las cerámicas está sin decorar y algunas podrían corresponder a un momento posterior al Neolítico. Sin embargo, los recipientes cerámicos decorados sí tienen una clara atribución neolítica: éstos presentan decoraciones incisas, impresiones, ungulaciones, cordones con digitaciones y ungulaciones, además de algunas decoraciones a la almagra. Los diseños forman generalmente zigzags, líneas paralelas verticales y motivos de series de impresiones (Fig. 3).

Los elementos líticos de sílex están constituidos por lascas, perforadores, láminas -muy pocas de ellas retocadas- y geométricos (triángulos, crecientes y trapecios) de gran formato. Destacan en el conjunto artefactual los materiales macrolíticos -percutores, martillos, pulidores, abrasivos, etc.-, así como núcleos y lascas de cuarcita sin retocar. Los útiles en hueso no son muy abundantes y son esencialmente punzones realizados sobre metápodos de ovicrápidos y astillas de huesos largos.

Los adornos están ampliamente representados y constituidos por: 1) cuentas de collar discoidales de caliza, dolomía y concha, 2) cuentas tubulares sobre hueso, 3) conchas perforadas (Columbella rustica, Conus mediterraneus, Cerastoderma edule y Glycymeris glycymeris) y 4) brazaletes de concha (Glycymeris glycymeris) y piedra.

La adscripción cronológica de la ocupación neolítica de la cavidad, a falta de dataciones absolutas, se ha realizado a partir de la caracterización de la cultura material. La Serreta forma parte de la veintena de yacimientos neolíticos que se distribuyen por la Región de Murcia, pero la mayoría de ellos se conocen por materiales de prospección, siendo difícil establecer la secuencia cultural de las poblaciones neolíticas de esta área. Entre estos yacimientos hay que referenciar el Abrigo Grande II del Barranco de los Grajos (Cieza), por la presencia de cerámica cardial indicativa de momentos del Neolítico inicial y la existencia de varias dataciones absolutas aunque éstas son excesivamente altas (Walker y Cuenca, 1977); y Los Abrigos del Pozo (Calasparra) a menos de $4 \mathrm{~km}$ de La Serreta aguas arriba, donde se han realizado varias intervenciones arqueológicas y cuyos niveles neolíticos han sido datados por $\mathrm{C}^{14}$. Los Abrigos del Pozo poseen una secuencia cultural que arrancaría desde el Paleolítico superior pasando por fases neolítica, calcolítica, de la Edad del Bronce, romana y medieval. La fase neolítica fue definida como los niveles $\mathrm{v}$ y vi; de este último, se obtuvo una datación sobre carbón vegetal de un hogar de $6260 \pm 120$ вр (Martínez Sánchez, 1994) que calibrado a $2 \sigma$ se situaría entre el 5476-4938 BC y la media en el $5206 \pm 143$ BC $^{4}$. En un trabajo reciente sobre un seísmo en el abrigo también se han obtenido dataciones absolutas, pero para un momento avanzado del Neolítico (5980 \pm 50 вр у $5820 \pm 50$ вр) cuyas medias son $4873 \pm 63$ вс у $4676 \pm 65(2 \sigma)$ respectivamente (Sánchez-Gómez et al., 2011). El material neolítico está formado por cerámica, elementos de sílex, cuarcita y brazaletes de caliza blanca. Los recipientes cerámicos son de tendencia globular, mayoritariamente sin decorar y aquellos que presentan decoraciones son incisas, acanaladas e impresiones con instrumento y ungulaciones (Martínez Sánchez, 1994). El registro material de La Serreta puede ser coetáneo con el de Los Abrigos del Pozo, teniendo en cuenta la proximidad y la similitud tanto en el tipo de materiales como las técnicas y estilos decorativos de las cerámicas.

Los registros materiales expuestos nos permiten situar la ocupación neolítica de La Serreta, según su materialidad, en un Neolítico antiguo que cronológicamente, a falta de dataciones absolutas, podría situarse entre el vi y v milenios cal BC.

\section{Material y métodos}

El conjunto estudiado está compuesto por varios tipos de materiales que requieren el desarrollo

${ }^{4}$ La media se ha obtenido con el programa CalPal Online (Danzeglocke et al., 2012). 
de metodologías analíticas concretas. Los restos analizados se pueden dividir en tres grandes grupos: brazaletes abandonados o fracturados en proceso de elaboración, brazaletes acabados y usados, y, por último, los útiles empleados en el proceso de manufactura de estos adornos.

Las materias primas estudiadas son fundamentalmente pétreas. La litología ha sido determinada con el análisis de visu, con ayuda de una lupa binocular para reconocer aquellas características de cada uno de los materiales -cristalizaciones, presencia de fósiles, laminaciones, etc.-. La clasificación petrológica macroscópica nos ha permitido realizar una caracterización de rango mayor de grupos litológicos: rocas sedimentarias y metamórficas de alto o bajo metamorfismo. No obstante, esta metodología debe de tratarse con precaución pues en ocasiones no es posible discernir las rocas ya que es necesario realizar análisis geoquímicos que son agresivos con el material arqueológico.

Para los brazaletes que se abandonaron o fracturaron en el proceso de manufactura se ha desarrollado una metodología concreta. Son piezas que se encuentran en una determinada fase del proceso de elaboración, por lo que podemos observar los estigmas técnicos del trabajo y su dinámica. Por ello, se han desarrollado diversas experimentaciones, como referentes para el reconocimiento de las distintas fases y estigmas técnicos de esta artesanía (MartínezSevilla, 2010; Martínez-Sevilla y Maeso, 2011 y Martínez-Sevilla, 2013a). La comparación entre las experimentaciones y el registro arqueológico se ha llevado a cabo a dos niveles:

1. La observación análoga y contrastación de los estigmas técnicos en los ejemplos experimentales y arqueológicos. Las piezas se han analizado con una lupa binocular (Leica EZ4 HD) y se han documentado gráficamente las trazas técnicas en ambos casos.

2. La comparación de la volumetría de las diferentes fases del proceso de elaboración, experimental y arqueológico, se ha llevado a cabo mediante dos métodos: en los casos experimentales, se mensuró el volumen en $\mathrm{cm}^{3}$ de las diferentes fases sumergiendo la pieza en un recipiente y midiendo la cantidad de agua que se desalojaba con una probeta (Martínez-Sevilla y Maeso, 2009); en las piezas arqueológicas, al tratarse de segmentos de formas cilíndricas se realizó un modelo en 3D por revolución con el programa Autocad que nos permitió calcular en volumen aproximado de las diversas fases de fabricación. De esta forma hemos podido comparar la cantidad de materia que se eliminaba en cada una de las fases de elaboración, con un margen de error admisible.

El número de brazaletes acabados y usados es muy reducido (15) por lo que no permite realizar un estudio estadístico de conjunto. Se han analizado materias primas, morfometrías y tipologías de cara a establecer paralelos formales con el resto de brazaletes de piedra estudiados en el s peninsular.

El último grupo de materiales estudiado está compuesto por diversas herramientas que se emplearon o pudieron usarse para la elaboración de los brazaletes de piedra. Su análisis ha consistido en una clasificación tecnofuncional agrupando tipológicamente los elementos según el trabajo en el que se emplearon. Esta clasificación se ha basado en su morfología, el estudio de las trazas sobre las superficies activas y la comparación con los ejemplos experimentales.

\section{La manufactura de brazaletes de piedra en el taller de La Serreta}

Desde la primera publicación de materiales arqueológicos de La Serreta ya se atisbó la presencia de fragmentos de brazaletes en proceso de elaboración (Salmerón, 1989). En los siguientes trabajos sobre la cavidad se hizo patente este hecho afirmándose que "...aunque no ha sido documentada un área específica dentro de la cavidad dedicada a la fabricación de estos elementos de adorno, la presencia de estos objetos permite inferir la existencia de un taller y documentan el proceso de trabajo requerido hasta adoptar su forma definitiva”... (Martínez Sánchez, 1996: 54). En las excavaciones posteriores se localizaron estratos de las ocupaciones neolíticas y una zona relacionada con el trabajo de elaboración de brazaletes. Esta asignación funcional viene dada por varias razones: la presencia de un pulidor o abrasivo de arenisca in situ (Fig. 2, n. ${ }^{\circ}$ 3); una acumulación de esbozos de brazaletes en diversas fases para su posterior transformación (Fig. 4); y la existencia de múltiples desechos y útiles empleados en esta actividad. El registro material neolítico está relacionado mayoritariamente con la fabricación de brazaletes de piedra, de ahí que podamos afirmar la existencia de un taller artesanal destinado a esta producción. 
72 F. Martínez-Sevilla y J. Salmerón / La artesanía de los brazaletes líticos de la Cueva-Sima de La Serreta (Cieza, Murcia)...
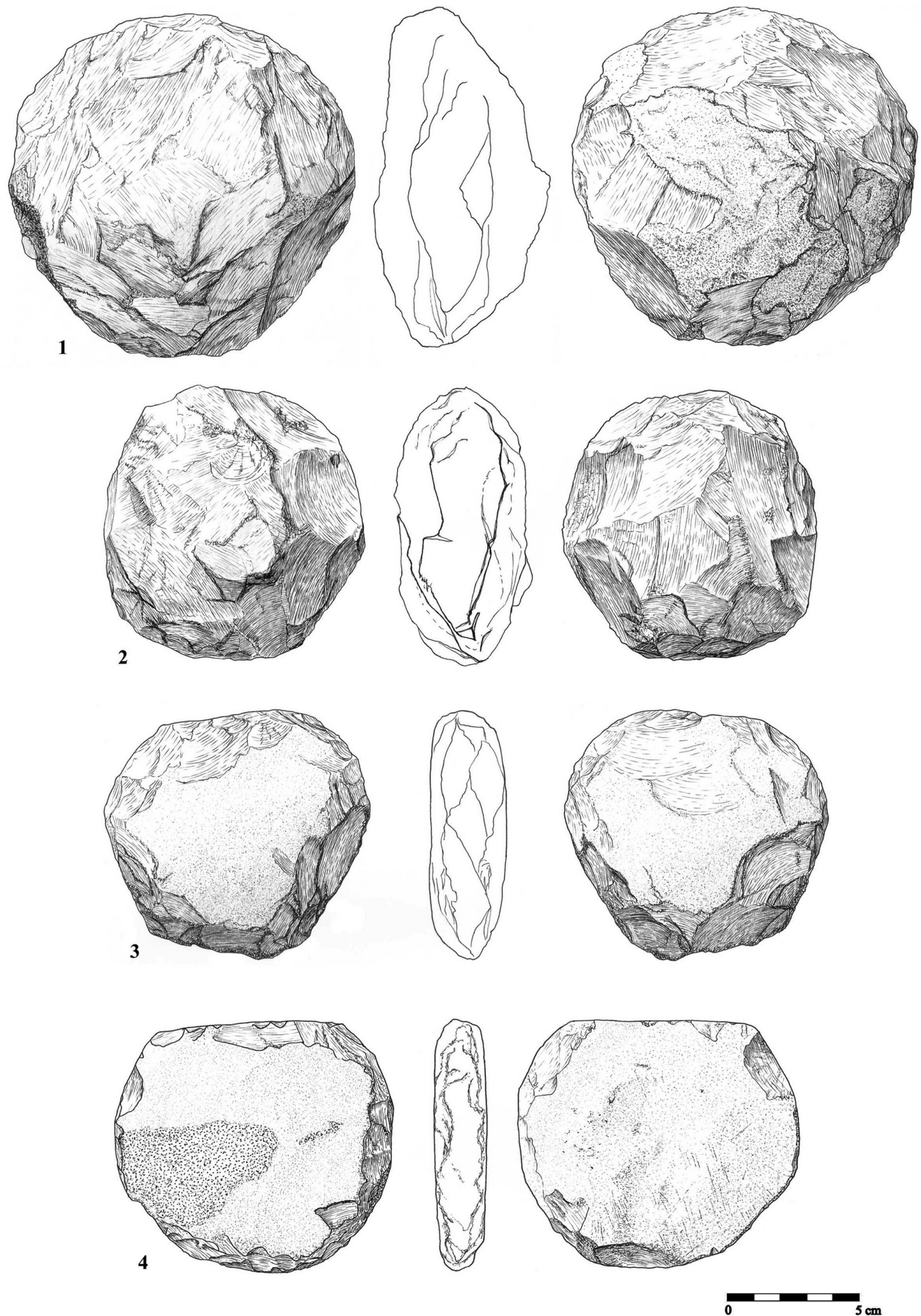

FIG. 4. Preformas de brazaletes: 1 y 2) talladas; 3 y 4) talladas y regularizadas mediante abrasión de sus caras (dibujo M. Belilty Molinos). 


\subsection{La tecnología de elaboración}

Ya ha sido descrita de forma detallada en trabajos previos, tanto en el caso de los brazaletes de piedra anchos (Martínez-Sevilla, 2013a) como estrechos (Martínez-Sevilla y Maeso, 2011). Aquí haremos referencia exclusivamente a los procesos tecnológicos concretos que se realizan en La Serreta y que difieren del resto de talleres estudiados.

El conjunto de brazaletes en proceso de elaboración estudiado está compuesto por dos litologías: 72 piezas son de caliza blanca micrítica y 7 de dolomía de color gris y negra. Ambas litologías son de carácter autóctono y pertenecen geológicamente al Cretácico superior. El sistema de abastecimiento documentado en el caso de las calizas es la extracción directa de la pared de la cavidad; las dolomías han podido igualmente recolectarse de un contexto geológico primario, pero la escasa representación podría indicar un aprovechamiento esporádico de los depósitos aluviales del río Segura.

El trabajo de cantería se ha documentado principalmente en la pared E de la cavidad. Las huellas que se conservan en esta zona indican que la extracción pudo llevarse a cabo con percusión directa mediante un percutor de piedra y ayudándose de cuñas o palancas, aprovechando los planos de sedimentación de las calizas (Fig. 2, n. ${ }^{\circ}$ 4). Las características de homogeneidad y su composición de grano fino favorecen la extracción de grandes lascas o lajas de caliza que posteriormente son talladas. Además de la información técnica sobre el abastecimiento hay que señalar varias cuestiones en relación a la zona donde se efectuaban los trabajos de cantería. Por un lado, la cantidad de roca extraída indica un uso prolongado de este taller de brazaletes y una mayor producción de la que se deduciría a partir de otros restos materiales. Por otro lado, la extracción de caliza está relacionada con uno de los motivos esquemáticos, llegando incluso a destruir parte de la pintura (Fig. 2, n. ${ }^{\circ}$ ), fechando de forma indirecta el motivo en un momento anterior o sincrónico a la propia artesanía de los brazaletes.

El conformado de las preformas se realiza mediante percusión directa con percutor duro y el método empleado es la talla bifacial alternante como puede observarse en las secciones de las piezas 1, 2 y 3 de la Fig. 4. Los elementos relacionados con la percusión -percutores- están ampliamente representados. Su materia prima es variada, desde rocas masivas como las ofitas hasta cantos rodados de cuarcita (Fig. 5, n. ${ }^{\text {os }} 1$ y 2) y caliza (Fig. 5, n. ${ }^{\text {o } 3) . ~}$ Son generalmente de morfología esférica u oblonga y las trazas de trabajo sobre las superficies activas están formadas por percusiones reiterativas y algunos levantamientos producto de la percusión. Hay que destacar dentro de este grupo algunos útiles polifuncionales, que se han utilizado para aplicar varias técnicas, como es el caso del percutor n. ${ }^{\circ} 3$ de la Fig. 5, usado para la percusión y la abrasión. Durante esta fase de talla se configuran formas circulares sobre las que se seguirá trabajando con otro tipo de técnicas más delicadas.

En La Serreta, a diferencia de otros talleres estudiados, no se utiliza el abujardado (Morgado y Martínez-Sevilla, 2013) o piqueteado para la regularización de las preformas sino la abrasión de ambas caras (Fig. 6, n. ${ }^{\text {os }} 1$ y 2). Esto es debido a que el abujardado es una técnica que se emplea preferiblemente en materiales con una textura cristalina -mármol o dolomías metamorfizadas- o clástica -areniscas, conglomerados, etc.- que requieren de esta labor. Sin embargo, la materia prima usada en La Serreta no permite aplicar esta técnica, pues se trata de calizas y dolomías lodosas de grano muy fino -micríticas-. La abrasión se lleva a cabo con un bloque de arenisca (Fig. 8, n. ${ }^{\circ}$ 1). Estos útiles se han localizado en la cavidad, siendo varios y de diversos tamańos, pero destaca uno ubicado in situ, su situación cercana a los desechos de brazaletes, a las preformas almacenadas y sus trazas de uso lo relacionan directamente con esta actividad (Fig. 2, n. ${ }^{\circ}$ 3). El trabajo de abrasión se realiza longitudinalmente al eje del abrasivo o pulidor y genera huellas paralelas en la superficie de las preformas (Fig. $\left.6, n .^{\circ} 1 \mathrm{~A}\right)$, en los casos en los que se invierte el eje de la preforma las huellas paralelas se entrecruzan de manera caótica (Fig. 6, n. ${ }^{\circ} 2$ y в). El gran número de lascas y núcleos de cuarcita documentado habría que ponerlo en relación con la abrasión. Estas lascas se transforman en arenas abrasivas mediante el triturado, ya que las arenas que se localizan en las inmediaciones del taller son de origen sedimentario y no abrasivas. Una vez regularizadas las caras y los bordes de la pieza se incide en la parte central de la preforma formando dos concavidades enfrentadas que preparan la pieza para la posterior perforación (Fig. 6, n. ${ }^{\text {os }} 3$ y 4 ). 
74 F. Martínez-Sevilla y J. Salmerón / La artesanía de los brazaletes líticos de la Cueva-Sima de La Serreta (Cieza, Murcia)...
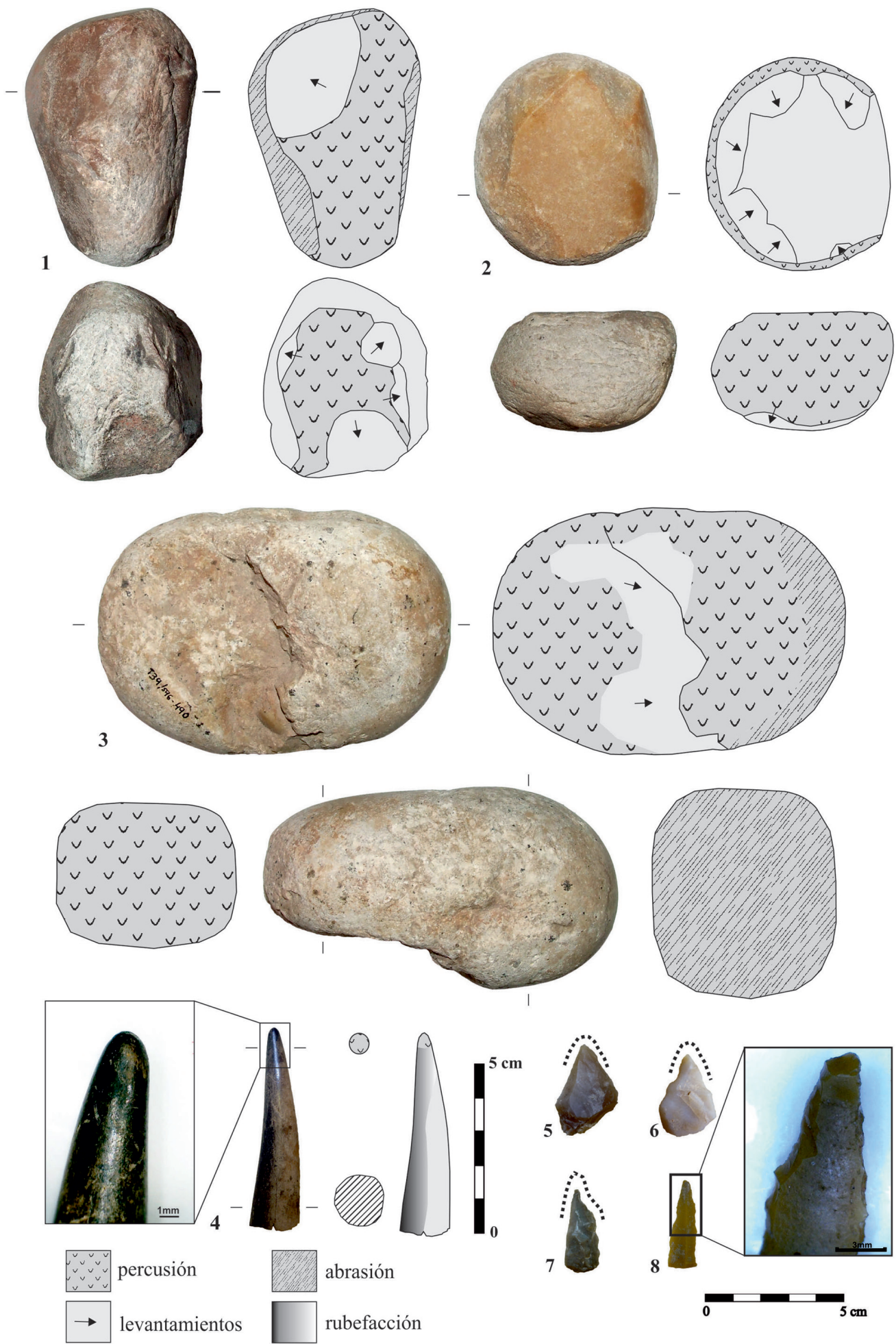

Fig. 5. Útiles empleados en trabajos de percusión y perforación: 1 y 2) percutores de cuarcita; 3) percutor de caliza; 4) candil de ciervo; 5-8) perforadores de silex. 

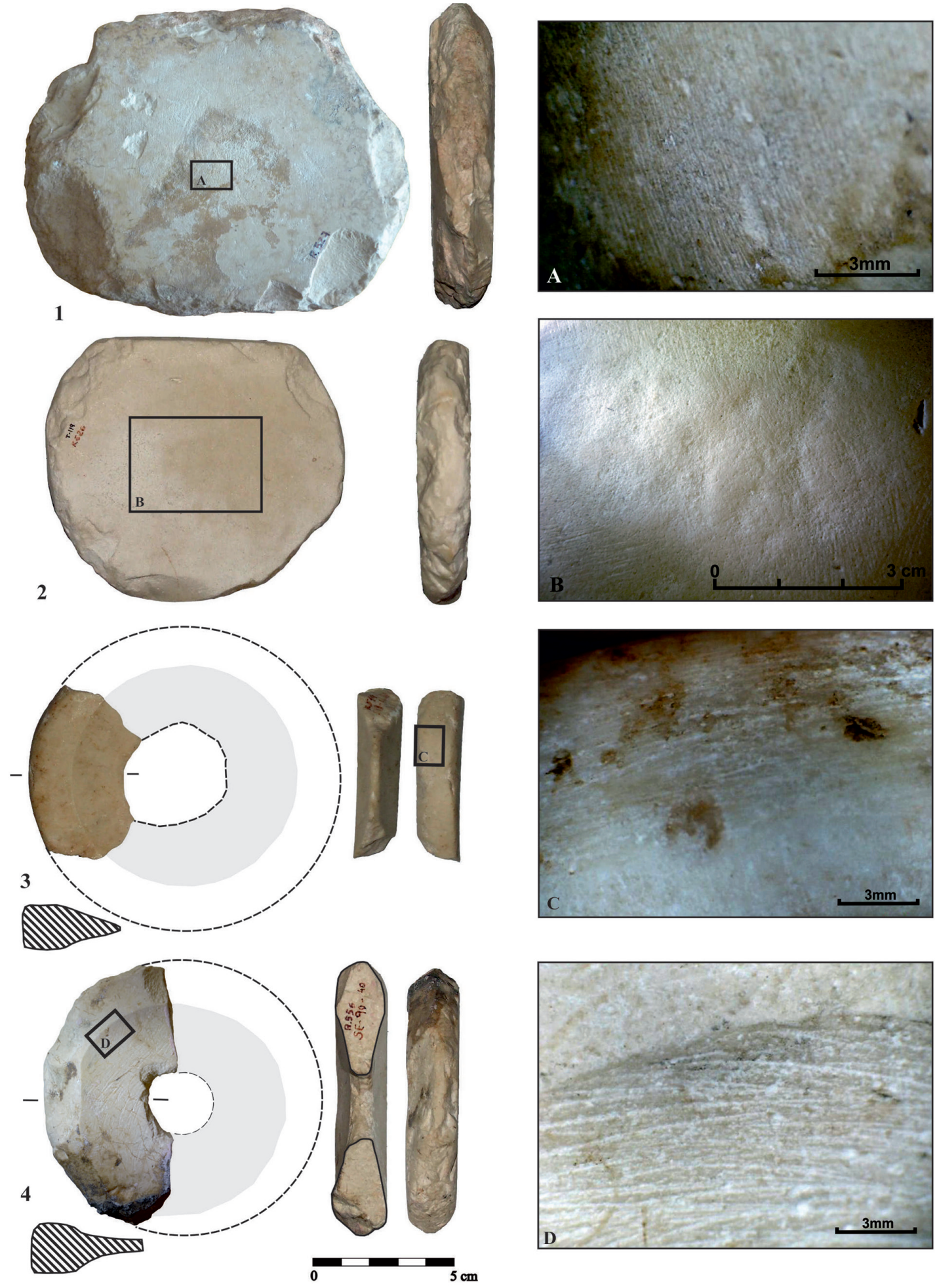

Fig. 6. Preformas de brazaletes y huellas técnicas: 1 y 2) regularizadas mediante abrasión de las caras; 3 y 4) creación de concavidades por abrasión y huellas técnicas. 
El reconocimiento arqueológico de las técnicas de perforación para la elaboración de brazaletes es complicado, ya que en la mayoría de los casos sólo quedan pruebas indirectas de ello o son deducidas a través de la propia lógica tecnológica. Una de las piezas en proceso documentadas en La Serreta (Fig. 3, n. $^{\circ}$ ) junto con varios perforadores en sílex indicaría el uso del taladro para realizar el orificio (Fig. 5, n. $\left.{ }^{\text {os }} 5-8\right)$.

En el caso que nos ocupa, el ensanchado del orificio se realiza mediante dos procedimientos: con percusión indirecta en los primeros momentos y finalmente con presión. El trabajo de percusión indirecta se ejecuta con un candil de ciervo, probablemente enmangado. Este útil ha sido identificado en el yacimiento, y presenta un tratamiento térmico de la punta con fuego y marcas de impactos reiterados (Fig. 5, n. ${ }^{\circ}$ 4). La percusión se efectúa en el orificio antes creado con una dinámica de trabajo circular a esta abertura y alternante en ambas caras de la pieza (Fig. 7, n. ${ }^{\circ}$ 1). De esta forma se van extrayendo pequeñas lascas y agrandando el contorno interior, las trazas de este proceso son fáciles de identificar y están formadas por pequeños levantamientos alternantes (Fig. 7, n.o 1 y A). Una vez ampliado el diámetro de la abertura con percusión indirecta se continúa trabajando con presión, técnica más delicada y que permite tener un mayor control de la pieza. Así se acaba regularizando la parte interior del brazalete y la prepara para la abrasión posterior (Fig. 7, n. $^{\circ}$ 2). La presión debió realizarse con un elemento apuntado, como un candil de ciervo, a tenor de las huellas de las piezas arqueológicas, constituidas por levantamientos continuos de menor tamaño a los generados con la percusión indirecta (Fig. 7, n. ${ }^{\circ} 2$ y в-C).

La abrasión y regularización del interior del brazalete es la técnica donde el taller de La Serreta muestra características propias con respecto al resto de talleres conocidos hasta el momento. En otros talleres, como la cueva de Los Mármoles (Martínez-Sevilla, 2010) o La Molaina (Carrasco et al., 2011), la abrasión interior siempre es perpendicular al eje del brazalete con marcas paralelas (Fig. 7, n. ${ }^{\circ}$ 3). Por el contrario, en La Serreta aparece una nueva técnica, la abrasión circular interior, que genera marcas paralelas longitudinales al eje del brazalete (Fig. 7, n.o 4). Este procedimiento es propio de este taller $y$, aunque posiblemente se trate de una innovación desarrollada en él, aparecen piezas elaboradas con ambas técnicas.

La abrasión paralela se lleva a cabo con un abrasivo de forma alargada u oblonga (Fig. 8, n. ${ }^{\circ}$ 3) y se trabaja friccionando de fuera hacia adentro alrededor de la pared interior del brazalete. La pieza en este proceso siempre se sujeta con la mano y se va moviendo simultáneamente respecto al abrasivo, por lo que la falta de control sobre la presión ejercida puede producir roturas fácilmente. Sin embargo, la abrasión circular se realiza con un abrasivo de arenisca de forma cónica que permanece estático ante el trabajo, siendo en este caso el brazalete el que rota sobre su propio eje (Fig. 8, n. $^{\circ} 2$ ). La presión en este caso se realiza en toda la superficie interior siendo más controlada. El estudio detallado del abrasivo ha permitido reconocer diversas marcas de fricción en su superficie, indicando el proceso de reducción continuo del interior del brazalete, también se han reconocido residuos endurecidos por el uso de agua para la abrasión y una parte abujardada aplanada en la base para su fijación.

Tanto los tests experimentales como el registro arqueológico indican que la abrasión circular tiene un índice de fractura más bajo que la abrasión paralela. Esto se debe, como hemos expuesto en el párrafo anterior, a que en la abrasión circular se realiza una presión sobre la mayor parte de la superficie interior del brazalete y es más controlada, mientras que la abrasión paralela se restringe a un único punto de fricción produciendo la fractura por tensión de la pieza. La abrasión interior se va alternando con la abrasión de la parte exterior de la pieza y se configura de forma tosca el brazalete.

\section{2. Tiempo, accidentes y artesanos}

Una de las cuestiones que más interés despierta desde nuestra óptica presente es: ¿cuánto tiempo se emplea en elaborar un brazalete? Pero seguramente la pregunta relevante sea: ¿verdaderamente el tiempo invertido en la fabricación de un objeto era importante para las sociedades del pasado? Probablemente no y el problema radica en que el planteamiento de ese tipo de cuestiones lo hacemos desde el presente, donde la producción está sometida a estándares como 'menor tiempo $=$ menor valor' y viceversa. Estas dos cuestiones entrañan 

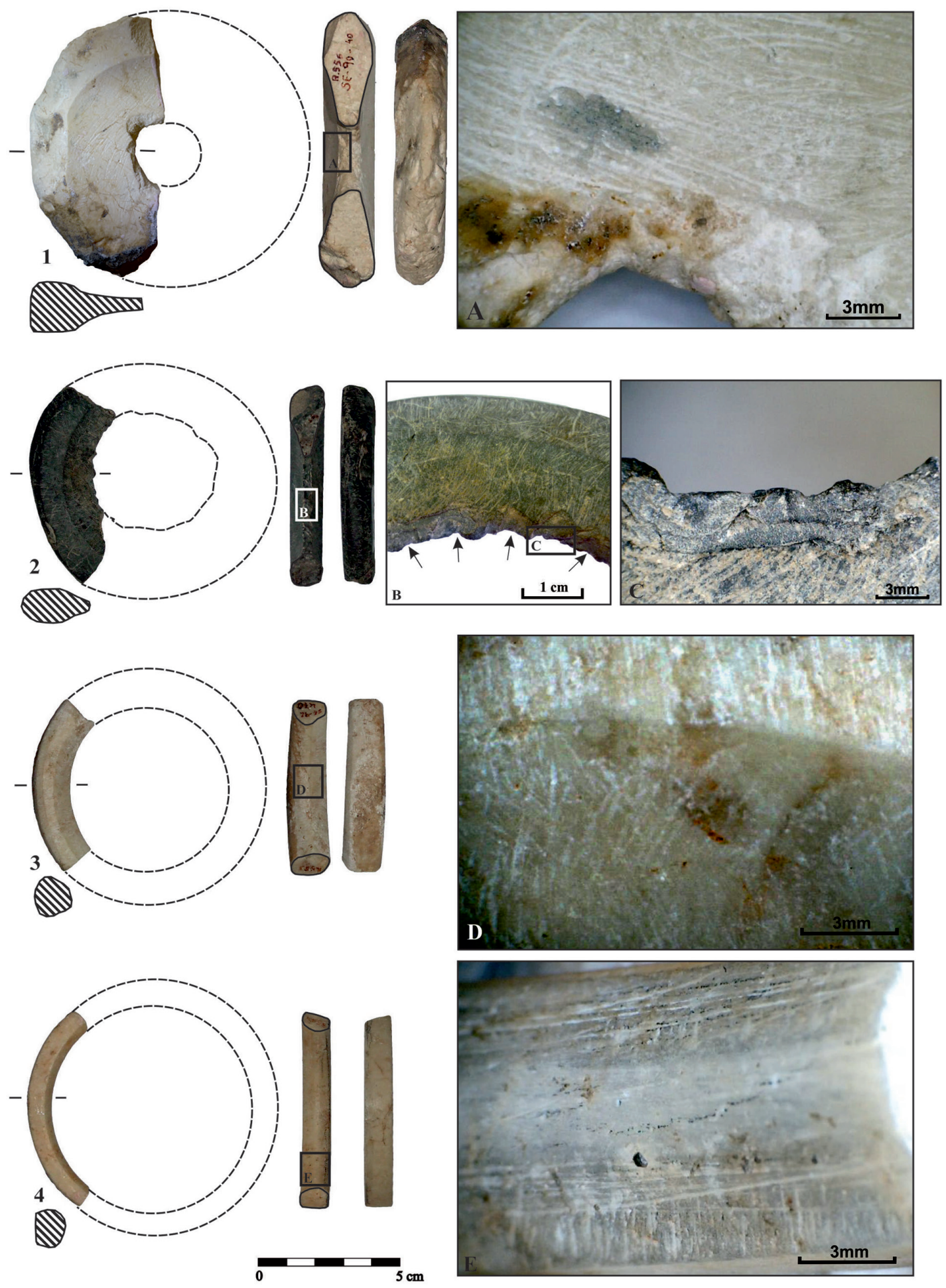

Fig. 7. Preformas de brazaletes y huellas técnicas: 1) ensanchado del orificio con percusión indirecta; 2) ensanchado del orificio central mediante presión; 3) abrasión interior paralela; 4) abrasión interior circular. 
78 F. Martínez-Sevilla y J. Salmerón / La artesanía de los brazaletes líticos de la Cueva-Sima de La Serreta (Cieza, Murcia)...
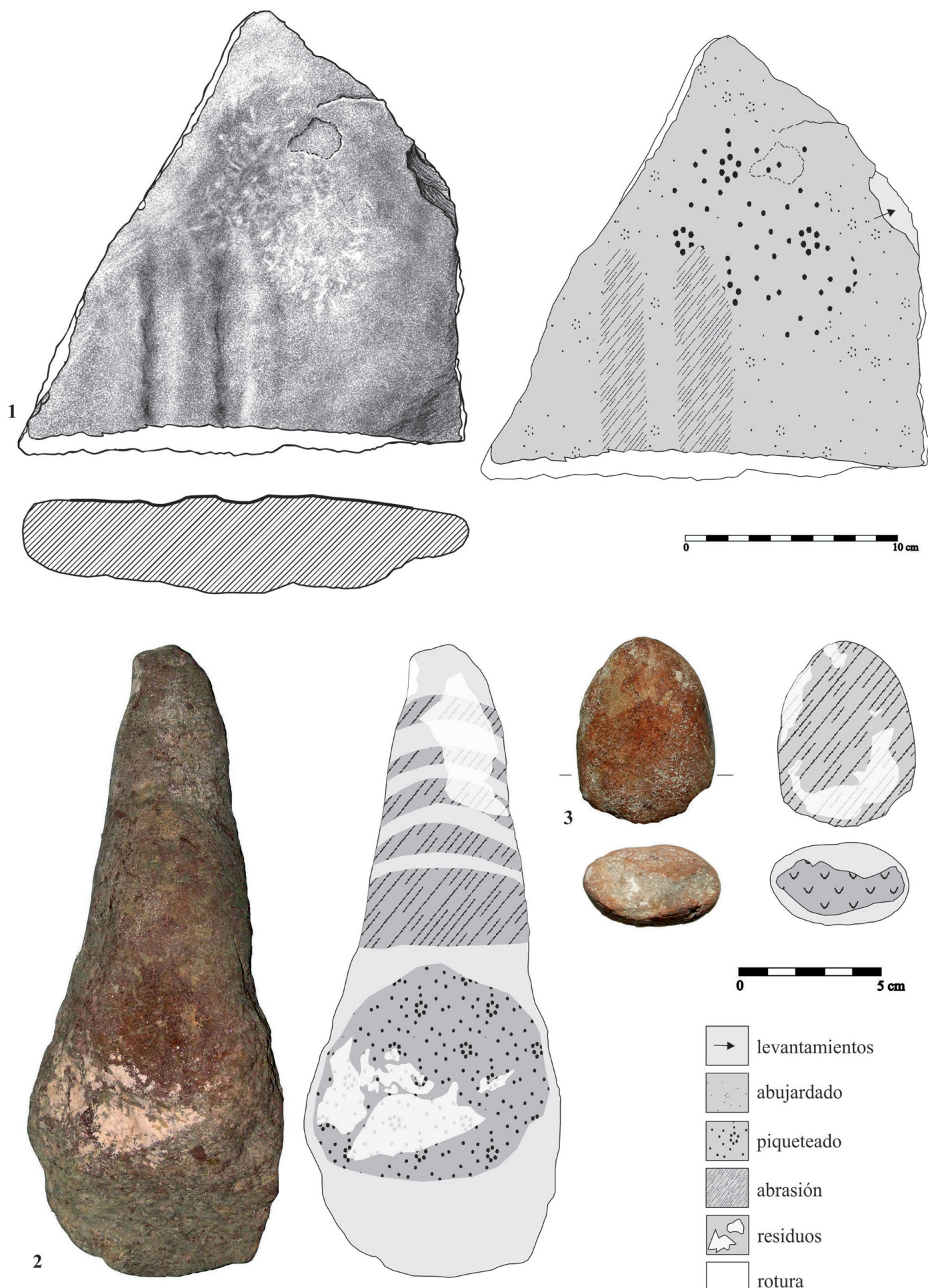

$\rightarrow$ levantamientos

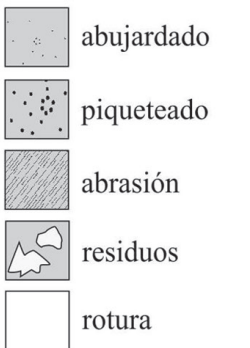

Fig. 8. Útiles empleados en trabajos de abrasión: 1) pulidor de calcarenita con ranuras de abrasión; 2 y 3) pulidores de arenisca. 
respuestas complejas y, por ello, vamos a intentar exponer las valoraciones deducidas a partir del registro arqueológico y de la experimentación sobre estas problemáticas.

A la hora de resolver la cuestión del tiempo empleado en la producción quizás el medio más acertado sea la experimentación, aunque siendo siempre conscientes de los problemas y límites que puede generar la comparación de procesos tan distantes en el tiempo y de habilidades artesanales seguramente tan dispares. En ese sentido,

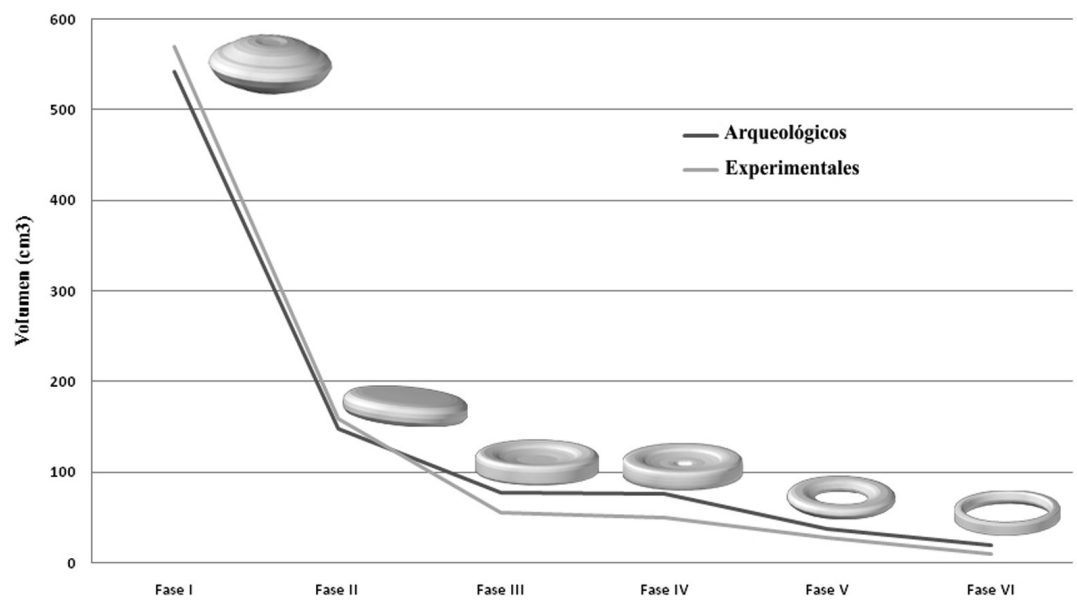

FIG. 9. Gráfico lineal que muestra la progresiva reducción del volumen de las piezas en cada fase del proceso de elaboración de los brazaletes de piedra.

las experimentaciones realizadas

hasta el momento pueden ser de gran ayuda ya que se han realizado siguiendo un protocolo exhaustivo de documentación.

Los brazaletes que aparecen en La Serreta son tecnotipológicamente estrechos. En los ensayos experimentales, precedidos de múltiples experiencias previas, se mensuró tanto el tiempo empleado en la manufactura de los brazaletes como el volumen de material que se eliminaba en cada fase de cara a comparar ambas producciones. En el tiempo empleado en la elaboración de un brazalete estrecho influyen múltiples variables: la materia prima, la destreza, la calidad de los útiles, etc. En nuestro caso se emplearon tiempos comprendidos entre las 6 y $3 \mathrm{~h}$ (Martínez-Sevilla y Maeso, 2009, 2011). Este hecho no se puede contrastar arqueológicamente, pero sí es posible comparar la volumetría de las diferentes fases del proceso de elaboración (experimental y arqueológico); esto puede mostrarnos la analogía tecnológica de ambas producciones (Fig. 9). El volumen se midió, como hemos descrito en el apartado metodológico, según diferentes procedimientos. La primera fase de reducción de la preforma tallada es el momento en el que más roca se elimina, seguido de la configuración de las concavidades enfrentadas y ambos pasos se corresponden con los trabajos de abrasión. En el resto de las fases, que son más progresivas y graduales, eliminan poco material. Esta comparación tiene sus límites ya que se trata de una emulación hecha desde el presente y los métodos de medición pueden generar errores, aunque la correlación entre ambos procesos es clara y reafirma que la reconstrucción de la cadena operativa es correcta.

La cuantificación de los restos arqueológicos de un mismo producto y su división en realidades dinámicas pueden ayudarnos a comprender el funcionamiento de un taller y la forma de trabajar de los artesanos. La Fig. 10 muestra la cadena operativa (Pelegrin et al., 1988) (deducida a través de estos desechos y de productos usados y amortizados). Los accidentes o los índices de fractura dentro del proceso pueden igualmente ayudarnos a comprender el proceso productivo y sus dificultades. Del conjunto de 93 brazaletes estudiados, las piezas fracturadas son $78-84 \%$ del total-, lo que demuestra que se trata de una artesanía con un alto número de accidentes, hecho que se ha constatado también experimentalmente. Los accidentes dentro del proceso general de elaboración son desiguales según las técnicas: mientras que la percusión indirecta y la presión ofrecen un alto índice de fractura, la fase en la que más roturas se producen (45) es la reducción interior mediante abrasión paralela. Como ya se expuso más arriba, la abrasión interior circular posiblemente sea una innovación tecnológica propia de este taller como reacción a esta dificultad.

Entre el registro material que estamos describiendo un grupo destacado son las preformas preparadas para ser transformadas con posterioridad. En este conjunto se agrupan dos tipos de preformas: las talladas (6) en forma de disco solamente trabajadas mediante percusión (Fig. 4, n. ${ }^{\text {os }} 1-2$ ) y las regularizadas mediante abrasión (3); sus caras 


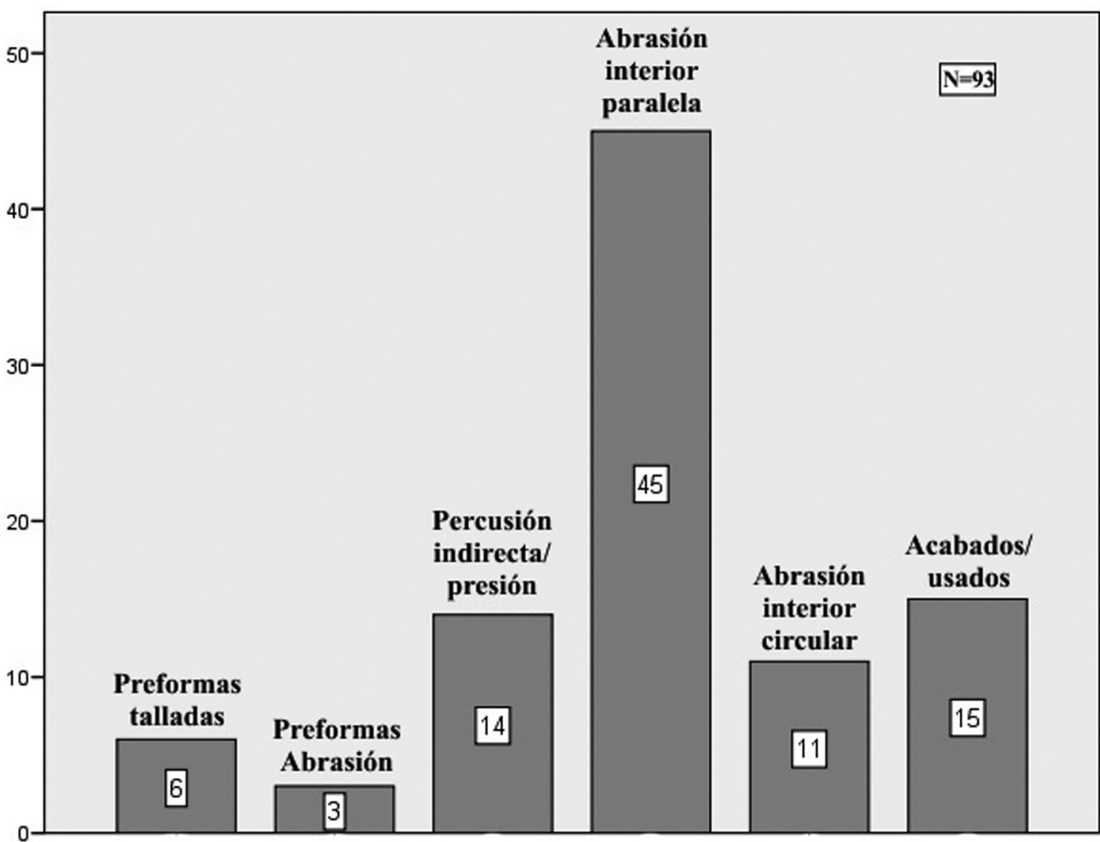

Fig. 10. Restos de brazaletes de piedra y su distribución según su fase de rotura o abandono.

y algunos de sus bordes están aplanados (Fig. 4, n. $\left.{ }^{\text {os }} 2-4\right)$. Esto indica que el proceso no se realiza de forma continua, sino que las diversas fases se dividen en el tiempo (al menos las dos primeras) y que posiblemente interviniese más de una persona en los trabajos, especialmente en aquellos en los que se requiere de menor habilidad como la regularización de las preformas por abrasión; las fases más delicadas se dejarían a los artesanos experimentados. El hecho de que aparezcan estas preformas almacenadas y apiladas ordenadamente podría demostrar la intencionalidad de ser trabajadas en un futuro y ello se relaciona con el uso intermitente de la cueva, probablemente estacional, para aprovechar otros recursos naturales de la zona.

\section{El conjunto de brazaletes acabados}

Los brazaletes acabados, usados y fragmentados, constituyen tan sólo el 16\% del total (Fig. 13). Las 15 piezas muestran litologías diferentes: 9 son calizas micríticas de la cavidad, 2 de caliza gris, 2 de mármol, 1 de esquisto y 1 indeterminado. Esta variabilidad contrasta con aquellos en proceso de elaboración, entre los que sólo se han determinado dos litologías, ambas de carácter autóctono. Las piezas más destacadas son los mármoles, tanto por la tipología y el acabado como por la litología (Fig. 11, n. ${ }^{\circ}$ 3). El análisis macroscópico de la materia prima indica que posiblemente se trate de mármol veteado procedente del complejo Nevado-Filábride y dentro de él de la Unidad de la Sabina (Puga, 1976). Estos materiales junto con las conchas marinas que aparecen en La Serreta indicarían la circulación de materiales, bien por la movilidad del grupo que ocupa la cueva o por relaciones con otros grupos humanos. La procedencia del resto de los brazaletes es más complicada de determinar. Las cuatro piezas de caliza micrítica que pertenecen a la cavidad fueron elaboradas en el mismo taller, según indican la materia prima, las marcas circulares en el interior -en algún caso- y la tipología.

Una característica que hay que destacar es la presencia de ocre en la parte interior de 6 de los brazaletes acabados. Estos restos no son intencionados, sino que se trata de residuos que se han adherido a la superficie del brazalete por el contacto con la piel. El procesado de ocre es otra de las actividades que se han documentado en la cavidad y que se ha relacionado con la preparación de los pigmentos para las pinturas rupestres ya que el triturado y la pulverización del ocre tiñe las manos de la persona que realiza este trabajo. Ésta sería la solución más lógica que justifica la presencia de ocre en la parte interior de algunos brazaletes acabados: el portador del brazalete estaría procesando el ocre e indirectamente el colorante se adhirió al mismo. Este hecho pone en relación las actividades la producción de brazaletes y el procesado de ocre.

La tipología del conjunto de brazaletes acabado no difiere de los encontrados en otros contextos arqueológicos del Sur y el Levante de la Península Ibérica. El lañado de algunos de estos 
elementos es igualmente común a muchos yacimientos, en La Serreta aparecen dos brazaletes reparados: uno de mármol (Fig. 11, n. ${ }^{\circ}$ 3) y otro de caliza elaborado allí mismo (Fig. 11, n.o 2). La reutilización de fragmentos de brazaletes para la elaboración de colgantes también es frecuente. El ejemplo que presentamos es un desecho de fabricación en el que se le ha intentado realizar una perforación para suspenderlo (Fig. 11, n. $\left.{ }^{\circ} 4\right)$. La mayoría de las reutilizaciones como colgantes se realiza sobre piezas usadas y amortizadas; en este caso, el brazalete que presentamos es un desecho de fabricación, por lo que los intentos de perforación no están destinados a la reparación del mismo sino que son un intento de elaboración de un colgante. Los diámetros interiores se han podido reconstruir en 14 de las piezas. La gráfica de la Fig. 12 muestra la relación de los diámetros interiores y exteriores de estos elementos en el cómputo general de los brazaletes estudiados hasta el momento. Se aprecia claramente cómo se ajustan a la normalidad de la recta-comprendidos entre los 60 y $85 \mathrm{~mm}-$ y es donde se agrupan la gran mayoría de los estudiados. No se puede extraer otra información al respecto salvo que la normalidad de la muestra se ajusta al resto conocido.

\section{El taller de La Serreta en el contexto del Sur peninsular}

Hasta ahora se han documentado 20 yacimientos con brazaletes en proceso de elaboración, que probablemente será una ínfima parte de la verdadera

realidad arqueológica. Los datos que poseemos sobre éstos son sesgados por la propia naturaleza de los hallazgos; en unos casos se han podido identificar propiamente talleres y en otros se trata de restos más o menos considerables. Estos yacimientos se distribuyen por el s peninsular y mayoritariamente se corresponden con los pocos asentamientos 'al aire libre' del Neolítico antiguo conocidos en esta área (Martínez-Sevilla, 2013b). De los talleres estudiados hasta el momento, La Serreta destaca por varias de sus características: el amplio registro arqueológico relacionado con la producción 


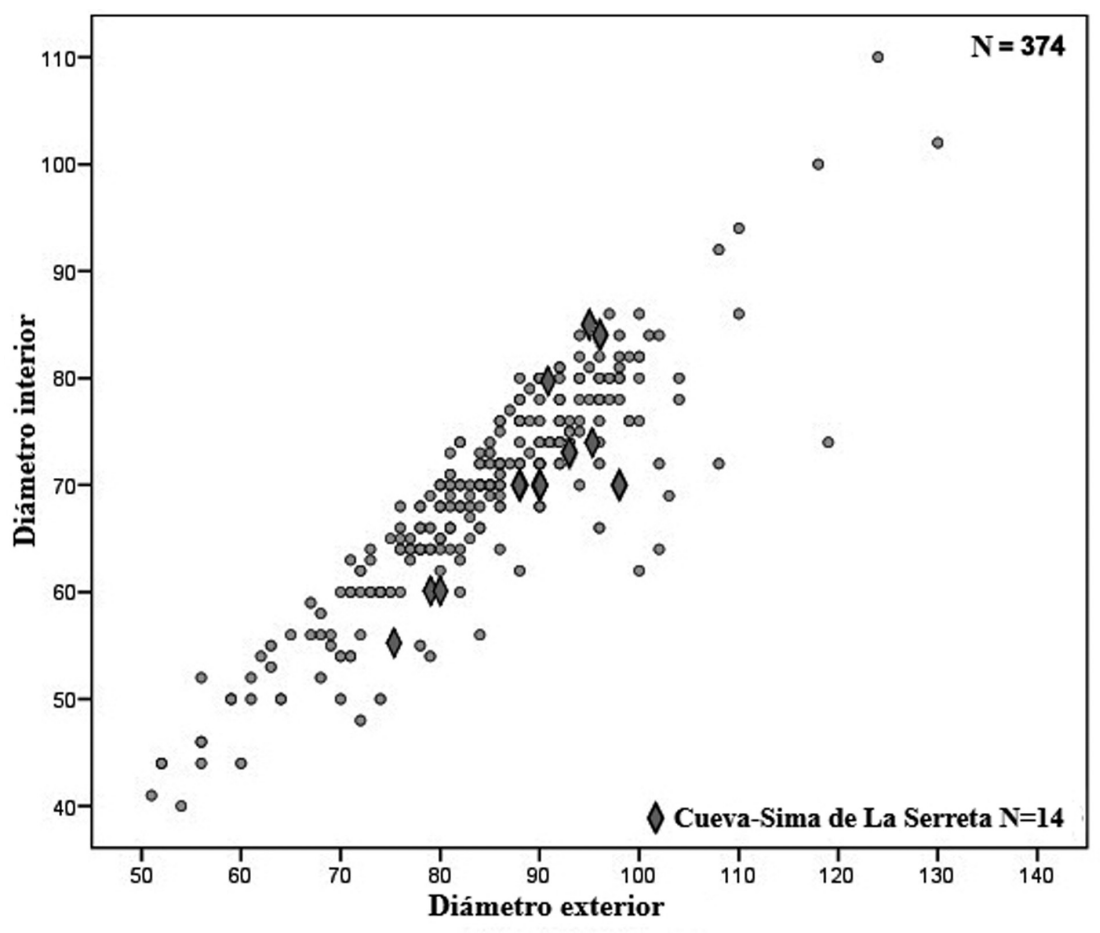

Fig. 12. Diagrama que muestra la relación entre el diámetro interior y exterior ( $\mathrm{mm}$ ) de los brazaletes de piedra del mediodía peninsular. de brazaletes tanto en proceso como de útiles empleados en él; su localización, ya que es el taller situado más al este de todo el conjunto; y finalmente las innovaciones técnicas que se desarrollan en él, independientes del resto.

Los brazaletes en su estado final aparecen en casi toda la Península Ibérica; sin embargo, los contextos de producción a priori se localizan exclusivamente en el s. Esta concentración se asimila a otras zonas donde se producen brazaletes de piedra como la Baja Normandía en Francia (Brurnez-Lanotte et al., 2005; Fromont, 2011) o el $\mathrm{N}$ de Italia (Micheli, 2011). Esta agrupación en la zona meridional de la Península Ibérica enfatiza la importancia de este adorno como identificador cultural de los grupos neolíticos

\begin{tabular}{|c|c|c|c|c|c|c|c|}
\hline N.o Inv. & Referencia & Litología & $\begin{array}{c}\begin{array}{c}\text { Altura } \\
(\mathbf{m m})\end{array} \\
\end{array}$ & $\begin{array}{c}\text { Grosor } \\
(\mathrm{mm})\end{array}$ & $\begin{array}{c}\text { Diámetro } \\
\text { Exterior }(\mathbf{m m})\end{array}$ & $\begin{array}{c}\text { Diámetro } \\
\text { Interior }(\mathrm{mm})\end{array}$ & Observaciones \\
\hline 29 & $1549-1550$ & Caliza micrítica & 9 & 12 & 70 & 88 & \\
\hline 30 & R.1632 & Esquisto & 9 & 11 & 73 & 93 & \\
\hline 31 & R.572 & Mármol & 6 & 41 & 84 & 96 & Restos de ocre interior \\
\hline 32 & 1847 & Caliza micrítica & 9 & 12 & 70 & 88 & Restos de ocre interior \\
\hline 93 & S951257 & Caliza micrítica & 6,5 & 11 & 80 & 93 & Restos de ocre interior \\
\hline 84 & S95379 & Caliza micrítica & 9,5 & 8,5 & 56 & 76 & \\
\hline 71 & S95481 & Caliza micrítica & 8 & 9 & 60 & 78 & \\
\hline 62 & S951590 & Caliza micrítica & 10 & 9 & 60 & 80 & \\
\hline 60 & SE-931254 & Caliza gris & $4+$ & 11 & 74 & 96 & Restos de ocre interior \\
\hline 47 & $3218-3219$ & Caliza micrítica & 10 & 7 & 70 & 90 & Restos de ocre interior \\
\hline 48 & 3221 & Caliza micrítica & 13 & 10 & 70 & 90 & \\
\hline 49 & 3220 & Caliza micrítica & 14 & 7 & 70 & 98 & \\
\hline 50 & 3222 & Caliza gris & 13 & 7 & 70 & 88 & \\
\hline 44 & $2697-2698$ & Mármol & 4 & 24 & 85 & 95 & $\begin{array}{l}\text { Restos de ocre } \\
\text { interior }\end{array}$ \\
\hline 42 & 4412 & & 12 & 7 & & & \\
\hline
\end{tabular}

FIG. 13. Relación de brazaletes acabados. 


\begin{tabular}{|c|c|c|c|c|c|c|c|}
\hline N. ${ }^{\circ}$ Inv. & Referencia & Litología & $\begin{array}{c}\text { Fase } \\
\text { tecnológica }\end{array}$ & $\begin{array}{l}\text { Largo } \\
(\mathrm{mm})\end{array}$ & $\begin{array}{l}\text { Ancho } \\
(\mathrm{mm})\end{array}$ & $\begin{array}{l}\text { Grosor } \\
(\mathbf{m m})\end{array}$ & $\begin{array}{c}\text { Diámetro } \\
\text { exterior }(\mathrm{mm})\end{array}$ \\
\hline 1 & $\mathrm{~T}-352$ & Caliza micrítica & I & 123 & 123 & 62 & \\
\hline 2 & $\mathrm{~T}-352$ & Caliza micrítica & I & 112 & 122 & 49 & \\
\hline 3 & $\mathrm{~T}-352$ & Caliza micrítica & I & 108 & 108 & 45 & \\
\hline 4 & $\mathrm{~T}-352$ & Caliza micrítica & I & 97 & 93 & 47 & \\
\hline 5 & $\mathrm{~T}-352$ & Caliza micrítica & I & 106 & 113 & 36 & \\
\hline 6 & T-296 R.547 & Caliza gris & II & 89 & 99 & 28 & \\
\hline 7 & R.527 & Caliza micrítica & II & 118 & 101 & 24 & \\
\hline 8 & T-119 R.547 & Caliza micrítica & II & 105 & 105 & 17 & \\
\hline 9 & R.584 & Caliza micrítica & IV & 29 & & 10 & 90 \\
\hline 10 & R.549 & Caliza micrítica & IV & 33 & & 15 & 90 \\
\hline 11 & R.550 & Caliza micrítica & IV & 27 & & 16 & 100 \\
\hline 12 & R.551 & Caliza micrítica & IV & 23 & & 11 & 130 \\
\hline 13 & R.555 & Caliza micrítica & IV & 31 & & 14 & 140 \\
\hline 14 & R.557 & Caliza micrítica & IV & 34 & & 19 & 100 \\
\hline 15 & R.556 & Caliza micrítica & IV & 35 & & 17 & 95 \\
\hline 16 & R.552 & Caliza micrítica & $\mathrm{V}$ & 13 & & 10 & 110 \\
\hline 17 & R.553 & Caliza micrítica & V & 13 & & 14 & 90 \\
\hline 18 & R.554 & Caliza micrítica & V & 16 & & 13 & 90 \\
\hline 19 & R.571 & Caliza micrítica & V & 13 & & 9 & 100 \\
\hline 20 & R.546 & Caliza micrítica & V & 11 & & 8 & 94 \\
\hline 21 & R.555 (535-SE-90) & Caliza micrítica & V & 11 & & 8 & 100 \\
\hline 22 & R.547 & Caliza micrítica & V & 11 & & 9 & 94 \\
\hline 23 & R.548 & Caliza micrítica & V & 8 & & 9 & 82 \\
\hline 24 & R.570 & Caliza micrítica & $\mathrm{V}$ & 10 & & 10 & 90 \\
\hline 25 & R.558 & Caliza micrítica & V & 8 & & 10 & 110 \\
\hline 26 & 1551 & Caliza gris & V & 12 & & 11 & 88 \\
\hline 27 & R.569 & Caliza micrítica & $\mathrm{V}$ & 8 & & 8 & 84 \\
\hline 28 & R.5Y6 (S95-1217) & Dolomía negra & $\mathrm{V}$ & 27 & & 11 & 70 \\
\hline 33 & 1845 & Caliza micrítica & V & 8 & & 9 & 84 \\
\hline 34 & 1846 & Caliza micrítica & $\mathrm{V}$ & 11 & & 10 & 80 \\
\hline 35 & 4414 & Caliza micrítica & IV & 36 & & 13 & 96 \\
\hline 36 & 4413 & Dolomía negra & IV & 23 & & 12 & 100 \\
\hline 37 & 4410 & Caliza micrítica & $\mathrm{V}$ & 13 & & 10 & 70 \\
\hline 38 & 4409 & Caliza micrítica & $\mathrm{V}$ & 14 & & 10 & 110 \\
\hline 39 & 4407 & Caliza micrítica & V & 13 & & 8 & 92 \\
\hline 40 & 4408 & Caliza micrítica & V & 9 & & 8 & 80 \\
\hline 41 & 4411 & Caliza micrítica & V & 9 & & 8 & \\
\hline 43 & SE-96 NI-2934 & Caliza micrítica & $\mathrm{V}$ & 13 & & 11 & 100 \\
\hline 45 & 3216 & Caliza micrítica & V & 9 & & 10 & 90 \\
\hline 46 & 3217 & Caliza micrítica & $\mathrm{V}$ & 11 & & 7 & 78 \\
\hline 51 & 1074 & Caliza micrítica & V & 17 & & 7 & \\
\hline
\end{tabular}




\begin{tabular}{|c|c|c|c|c|c|c|c|}
\hline N..$^{0}$ Inv. & Referencia & Litología & $\begin{array}{c}\text { Fase } \\
\text { tecnológica }\end{array}$ & $\begin{array}{l}\text { Largo } \\
(\mathrm{mm})\end{array}$ & $\begin{array}{c}\text { Ancho } \\
\text { (mm) }\end{array}$ & $\begin{array}{l}\text { Grosor } \\
(\mathrm{mm})\end{array}$ & $\begin{array}{c}\text { Diámetro } \\
\text { exterior }(\mathrm{mm})\end{array}$ \\
\hline 52 & 3345 & Caliza micrítica & $\mathrm{V}$ & 7 & & 9 & 110 \\
\hline 53 & 3346 & Caliza micrítica & $\mathrm{V}$ & 8 & & 10 & 70 \\
\hline 54 & $7-2-97$ & Caliza micrítica & $\mathrm{I}$ & 96 & 88 & 32 & \\
\hline 55 & N-5 19 & Caliza micrítica & IV & 13 & & 11 & 100 \\
\hline 56 & & Caliza micrítica & VI & 11 & & 10 & 90 \\
\hline 57 & 122 & Caliza micrítica & VI & 35 & 65 & 29 & 111 \\
\hline 58 & 161 & Caliza micrítica & $\mathrm{V}$ & 13 & & 11 & 100 \\
\hline 59 & $\mathrm{~N}-4-5$ & Caliza micrítica & $\mathrm{V}$ & 9 & & 12 & 87 \\
\hline 61 & SE-459 T8 & Caliza gris & $\mathrm{V}$ & 13 & & 7,5 & 87 \\
\hline 63 & S922105 & Caliza micrítica & V & 10 & & 10 & 45 \\
\hline 64 & S95483 & Caliza micrítica & $\mathrm{V}$ & 24 & & 13 & 93 \\
\hline 65 & SE-93-199 & Caliza micrítica & $\mathrm{V}$ & 22 & & 11 & 87 \\
\hline 66 & SE-92-2110 & Caliza gris & IV & 33 & & 14 & 112 \\
\hline 67 & SE-90-355 & Caliza micrítica & $\mathrm{V}$ & 15 & & 11 & 76 \\
\hline 68 & SE-93-769 & Caliza micrítica & $\mathrm{V}$ & 9 & & 12 & 84 \\
\hline 69 & S922303 & Caliza micrítica & $\mathrm{V}$ & 9 & & 12 & 69 \\
\hline 70 & S931771 & Caliza gris & $\mathrm{V}$ & 8 & & 8 & 69 \\
\hline 72 & S95898 & Caliza micrítica & $\mathrm{V}$ & 12 & & 10 & 84 \\
\hline 73 & S92365 & Caliza micrítica & $\mathrm{V}$ & 10 & & 10 & 107 \\
\hline 74 & S922477 & Caliza micrítica & $\mathrm{V}$ & 17 & & 10 & 56 \\
\hline 75 & S921259 & Caliza micrítica & $\mathrm{V}$ & 10 & & 9 & 75 \\
\hline 76 & S951256 & Caliza micrítica & $\mathrm{V}$ & 12 & & $7+$ & 50 \\
\hline 77 & S95340 & Caliza micrítica & $\mathrm{V}$ & 11 & & 10 & 68 \\
\hline 78 & S95339 & Caliza micrítica & V & 10 & & 10 & 75 \\
\hline 79 & S951624 & Caliza micrítica & $\mathrm{V}$ & 12 & & 8 & 100 \\
\hline 80 & S92302 & Caliza micrítica & $\mathrm{V}$ & 10 & & 10 & 62 \\
\hline 81 & Se-90536 & Caliza micrítica & $\mathrm{V}$ & 15 & & 9 & 106 \\
\hline 82 & S932500 & Caliza micrítica & $\mathrm{V}$ & 11 & & 8,5 & 81 \\
\hline 83 & SE-921464 & Caliza micrítica & $\mathrm{V}$ & 12 & & 11 & 81 \\
\hline 85 & S-922794 & Caliza micrítica & IV & 12 & & 8 & 68 \\
\hline 86 & SE-92-2884 & Caliza micrítica & $\mathrm{V}$ & 14 & & 13 & 83 \\
\hline 87 & S95341 & Caliza micrítica & $\mathrm{V}$ & 13 & & 10 & 82 \\
\hline 88 & S921110 & Caliza micrítica & $\mathrm{V}$ & 16 & & 11 & 43 \\
\hline 89 & SE-93682 & Caliza micrítica & $\mathrm{V}$ & 13 & & 9 & 68 \\
\hline 90 & S951293 & Caliza micrítica & $\mathrm{V}$ & 8 & & 9 & 85 \\
\hline 91 & SE-931150 & Caliza micrítica & $\mathrm{V}$ & 11 & & 11 & 68 \\
\hline 92 & S95585 & Caliza micrítica & $\mathrm{V}$ & 8 & & 10 & 62 \\
\hline
\end{tabular}

FIG. 14. Piezas abandonadas o desechadas en diferentes fases del proceso de elaboración: I) preformas talladas; II) preformas con las caras regularizadas por abrasión; III) concavidad central por abrasión; IV) ensanchado del orificio central; V) regularización del orificio central por abrasión; VI) pulido final. 
de esta área y permite definir redes de circulación con otros grupos peninsulares. En este contexto, el taller de La Serreta se enclava en un punto intermedio entre dos realidades arqueológicas diferenciadas el Neolítico andaluz y el valenciano. Las diferencias entre ambas zonas geográficas están constituidas por matices del registro material. La producción de brazaletes es una de esas diferencias que habría que remarcar, pues no se han documentado talleres en la zona levantina a pesar de poseer una fuerte tradición en las investigaciones sobre el Neolítico y en especial sobre los objetos de adorno (Pascual, 1996a, 1996b, 1998a y 1998b).

La presencia de brazaletes acabados en La Serreta, procedentes de afloramientos geológicos como el Nevado-Filábride, remarca la importancia de la circulación de estos objetos entre el s y el Levante.

\section{Conclusiones}

El análisis del registro material neolítico de La Serreta ha puesto en evidencia la existencia de un taller de brazaletes de piedra en la cavidad. Los desechos de la producción y el amplio número de útiles relacionado con este trabajo resaltan la importancia de esta artesanía en el yacimiento. Podemos situar su cronología, a tenor de sus registros materiales, dentro de un Neolítico antiguo que se viene vinculando a partir de la segunda mitad del vi milenio cal вс.

Las conclusiones sobre la artesanía en este taller en particular son varias. La extracción de las calizas en la propia cavidad es una de las características a resaltar por varias razones. Por un lado, podría ser uno de motivos por los que se encuentra enclavado el taller en esta cueva; la cantidad de roca extraída indica un uso prolongado del sitio y una mayor producción de la que se deduciría a partir de otros restos materiales. Además, la extracción de caliza está vinculada con uno de los motivos rupestres esquemáticos, llegando incluso a destruir parte de la pintura. Se puede atribuir de forma indirecta una datación anterior o sincrónica a la propia artesanía de los brazaletes.

La abrasión interior circular es otra de las particularidades de La Serreta, si lo comparamos con otros talleres estudiados, ya que se trata de un procedimiento tecnológico que posiblemente se desarrolle como solución al alto índice de fracturas que provoca la abrasión paralela interior. Este procedimiento puede ayudar a reconocer productos procedentes de este taller o grupos humanos afines al taller, pudiéndose considerar como un elemento característico, ya que hasta el momento no se ha identificado en ningún otro lugar.

La presencia de preformas almacenadas para su posterior transformación indica que todo el proceso no se realiza de manera continua sino que las diversas fases se dividen en el tiempo, interviniendo posiblemente más de una persona en el proceso. Estas preformas también permiten extraer algunas conclusiones sobre la ocupación neolítica de la cavidad. En este sentido, podemos afirmar que probablemente se trate de un hábitat estacional relacionado con el aprovechamiento de los recursos locales. En esta misma línea, las armaduras de flechas constituidas por geométricos de gran tamaño se deben poner en relación con la caza, mientras que los restos de fauna doméstica están vinculados a las actividades ganaderas.

La documentación de brazaletes acabados de materias primas alóctonas, como el mármol, indica la circulación de estos adornos. Este fenómeno se ha identificado en otros talleres en los que los brazaletes en proceso son de rocas autóctonas y algunos de los acabados son foráneos. La presencia y localización, en el interior de brazaletes acabados, de restos de ocre relaciona también a este adorno y su producción con la transformación del ocre.

\section{Bibliografía}

Burnez-Lanotte, L.; Caspar, J. P. y Vanguestaine, M. (2005): “Technologie des anneaux en schiste dans le groupe de Blicquy/Villeneuve-Saint-Germain à Vauxet-Borset (Hesbaye, Belgique). Interférences de soussystèmes techniques", Bulletin de la Société Préhistorique Française, 102, pp. 551-596.

http://dx.doi.org/10.3406/bspf.2005.13142

Carrasco, J.; Martínez-Sevilla, F. y Gámiz, J. (2011): "Algunas cuestiones sobre los asentamientos al aire libre del Neolítico Antiguo/Medio en 'La Vega' de Granada”, Antiquitas, 23, pp. 47-71.

Danzeglocke, U.; Jöris, O. y Weninger, B. (2012): "CalPal-2007online” (http://www.calpal-online.de/; accessed 04/2013).

Fromont, N. (2011): Anneaux et cultures du Néolithique ancien. Production, circulation et utilisation entre massifs 
ardennais et armoricanin. BAR, Int. Ser., 2599. Oxford: Archaeopress.

García del Toro, J. (1988): "Las pinturas rupestres de la Cueva-Sima de 'La Serreta' (Cieza, Murcia). Estudio preliminar", Anales de Prehistoria y Arqueología, 4, pp. 33-40.

Gavilán, B.; Molina, A. y Rafael, J. J. (1997): "Algunos elementos de adorno del Neolítico andaluz". En II Congreso de Arqueología Peninsular (Zamora 1996). T. II. Neolítico, Calcolítico y Bronce. Gavá, pp. 83-87.

Gavilán, B. y Rafael, J. J. (1999): “Análisis de la industria ornamental de la Cueva de los Murciélagos de Zuheros (Córdoba)". En II Congrés del Neolitic a la Península Ibèrica (Valencia 1999). Saguntum-PLAV, Extra 2. Valencia, pp. 157-162.

GoÑI, A. (1999): "Los elementos de adorno personal: materias primas, procesos de fabricación y tipología de la producción ornamental”. En Cámalich, M. D. y MarTín Socas, D. (coords.): El territorio almeriense desde los inicios de la producción hasta fines de la antigüedad. Un modelo: La depresión de Vera y cuenca del rio Almanzora. Monografías de Arqueología, 6. Sevilla: Junta de Andalucía, pp. 251-267.

GoÑi, A.; Rodríguez Rodríguez, A. M.; CÁmalich, D.; Martín Socas, D. y Francisco, M. I. (1999): "La tecnología de los elementos de adorno personal en materias minerales durante el Neolítico medio. El ejemplo del poblado de Cabecicos Negros (Almería)". En II Congrés del Neolític a la Peninsula Ibèrica (Valencia 1999). Saguntum-PLAV, Extra 2. Valencia, pp. 163-170.

Jiménez Gómez, M. C. (1979): "Los brazaletes de Piedra Blanca y su contexto en la Espańa mediterránea”. En $X V$ Congreso Nacional de Arqueología (Lugo 1977). Zaragoza, pp. 531-544.

Martínez SÁnchez, C. (1994): "Nueva datación de $C^{14}$ para el Neolítico de Murcia: los Abrigos del Pozo (Calasparra)", Trabajos de Prehistoria, 52, pp. 157-161. http://dx.doi.org/10.3989/tp.1994.v51.i1.481

Martínez SÁnchez, C. (1996): "Cueva-sima La Serreta (Cieza): un yacimiento neolítico en la vega alta del Segura”, Memorias de Arqueología de Murcia, 5, pp. 44-56.

Martínez-Sevilla, F. (2010): "Un taller neolítico de brazaletes de piedra en la cueva de Los Mármoles (Priego de Córdoba)", Antiquitas, 22, pp. 35-55.

Martínez-Sevilla, F. (2013a): "La tecnología de elaboración de los brazaletes anchos de piedra neolíticos del sur de la Península Ibérica”. En Palomo, A.; Piqué, R. y Terradas, X. (eds.): Experimentación en arqueología. Estudio y difusión del pasado. Sèrie Monogràfica del MAC. Gerona, pp. 87-96.

Martínez-Sevilla, F. (2013b): "Los contextos de producción de brazaletes de piedra neolíticos en el Sur de la Península Ibérica y sus implicaciones socioeconómicas". En II Congreso de Prehistoria de Andalucia (Antequera, 2012). Málaga, pp. 303-313.
Martínez-Sevilla, F. y Maeso, C. (2009): "Experimentación aplicada a un problema arqueológico: tecnología de los brazaletes de sección plana en el Neolítico del Sur de la Península Ibérica”. En II Jornadas de Jóvenes en Investigación Arqueológica (Madrid 2009). Madrid, t. II, pp. 509-515.

Martínez-Sevilla, F. y Maeso, C. (2011): “Tecnología para la elaboración de brazaletes líticos de sección plana en el Neolítico del Sur de la Península Ibérica desde la experimentación". En Morgado, A.; Baena, J. y GarcÍA, D. (eds.): Investigación experimental aplicada a la Arqueología, pp. 131-139.

Mateo, M. A. (1996): "Las pinturas rupestres de La Serreta, Cieza (Murcia)”, Zephyrus, Xliv-Xuv, pp. 241-250.

Mateo, M. A. (1997): "El arte rupestre de la cueva de La Serreta (Cieza, Murcia)", Memorias de Arqueología, 7, Madrid, pp. 23-37.

Micheli, R. (2011): "Raw materials, personal ornaments and neolithic groups: some observations on stone bracelets of the Early Neolithic of northern Italy". En Congrés Internacional Xarxes al Neolitic. Rubricatum, 5, pp. 241-248.

Morgado, A. y Martínez-Sevilla, F. (2013): “¡Percutores, astillados sobre núcleos o bujardas? Las bujardas de sílex de la Prehistoria reciente de la Península Ibérica: definición, experimentación y significado tecnoeconómico”. En Palomo, A.; Piqué, R. y Terradas, X. (eds.): Experimentación en arqueología. Estudio y difusión del pasado. Sèrie Monogràfica del MAc. Gerona, pp. 97-107.

Pascual, J. L. (1996a): "Los anillos neolíticos de la Península Ibérica”. En I Congrés del Neolític a la Península Ibérica (Gava-Bellaterra, 1995). Rubricatum, 1 (I), pp. 279-289.

Pascual, J. L. (1996b): "Los adornos del Neolítico I en el País Valenciano", Recerques del Museu d'Alcoi, v, pp. 17-52.

Pascual, J. L. (1998a): Utillaje óseo, adornos e idolos neoliticos valencianos. Serie de Trabajos Varios del sip, 95. Valencia.

Pascual, J. L. (1998b): "Las fuentes de materia prima de los adornos de lignito prehistóricos de la vertiente mediterránea peninsular entre el Ebro y el Segura”. En $2^{a}$ Reunió de Traball sobre aprovisionament de recursos lític a la Prehistòria. Rubricatum, 2, pp. 153-160.

Pelegrin, J.; Karlin, C. y Bodu, P. (1988): "chaîne opérative’: un outil pour le préhistorien”. En Tixier, J. (ed.): Technologie Préhistorique, Notes et Monògraphies Téchniques, 25, pp. 55-62.

PugA, E. (1976): Investigaciones petrológicas en Sierra Nevada occidental. Colección Tesis doctorales, 133. Granada: Univ. de Granada.

SAlmerón, J. (1989): "Cultura material y pintura rupestre en Los Almadenes (Cieza, Murcia)”. En XIX Congreso Nacional de Arqueología. Zaragoza, t. II, pp. 169-178. 
Salmerón, J. (1993): "La cueva-sima de La Serreta. Un hábitat cavernícola de época tardo-romana”, Revista de Arqueología, 143, pp. 54-56.

Salmerón, J. (1994): "Cueva-sima de La Serreta (Cieza)". En $v$ Jornadas de Arqueología Regional (Murcia 1994). Murcia, pp. 8-9.

SALMERón, J. (1995a): "Las construcciones tardorromanas de la cueva-sima de La Serreta (Cieza, Murcia) y su contexto", Antigüedad y Cristianismo, xII, pp. 563-578.

Salmerón, J. (1995b): "Cueva-Sima de La Serreta (Cieza)". En VI Jornadas de Arqueología Regional (Murcia 1995). Murcia, p. 29.

Salmerón, J. (1996): "Cueva-Sima de La Serreta (Cieza)". En VII Jornadas de Arqueología Regional (Murcia 1996). Murcia, p. 14.

Salmerón, J. (1997): "Cueva-Sima de La Serreta (Cieza)". En VII Jornadas de Arqueología Regional (Murcia 1997). Murcia, p. 16.

Salmerón, J. (1999): “La Cueva-Sima de La Serreta (Cieza) santuario de arte rupestre, hábitat neolítico y refugio tardorromano", Memorias de Arqueología, 8, pp. 140-154.

SAN Nicolás del Toro, M. (1985): "Las pinturas rupestres esquemáticas del abrigo del Pozo (Calasparra, Murcia)", Caesaraugusta, 61-62, pp. 95-118.
Sánchez Sánchez, J.; Fernández Saura, A.; López de Ochoa, M.; Capel, F. y Jiménez Bizada, J. M. (1975): "Hallazgos arqueológicos en la Sima-Cueva de La Serreta (Cieza)". En Comunicaciones sobre el Carst en la provincia de Murcia. Murcia: Dip. Prov. de Murcia, vol. I-1, pp. 83-87.

SÁnchez-Gómez, M.; Martínez Sánchez, C.; García García, F.; Peláez, J. A.; Pérez Valera, F.; Martínez Andreu, M. y Pérez Valera, L. (2011): "Evidence for a 4700-2100 вС palaeoearthquake recorder in a fluvial-archaeological sequence of the Segura River, se Spain", Quaternary International, 242, pp. 106-114. http://dx.doi.org/10.1016/j.quaint.2011.03.025

Teruel, M. S. (1986): "Objetos de adorno en el Neolítico de Andalucía Oriental. Síntesis tipológica”, Cuaderno de Prehistoria de la Univ. de Granada, 11, pp. 9-26.

Vera, J. C. y Martínez Fernández, M.a (2012): "El contexto de la producción y circulación de cerámicas y elementos de adorno en el Neolítico antiguo del sur de Córdoba", Rubricatum, 5, pp. 273-280.

Warker, M. y CuencA, A. (1977): "Nuevas fechas de C-14 para el sector de Alicante y Murcia", Trabajos sobre el Neógeno Cuaternario, 6, pp. 309-317. 